\title{
Strength, transformation toughening, and fracture dynamics of rocksalt-structure $\operatorname{Ti}_{1-x} \mathbf{A l}_{x} \mathbf{N}$ $(0 \leqslant x \leqslant 0.75)$ alloys
}

\author{
D. G. Sangiovanni $\odot,{ }^{1,2, *}$ F. Tasnádi, ${ }^{1}$ L. J. S. Johnson, ${ }^{3}$ M. Odén, ${ }^{1}$ and I. A. Abrikosov ${ }^{1}$ \\ ${ }^{1}$ Department of Physics, Chemistry and Biology (IFM) Linköping University, SE-581 83, Linköping, Sweden \\ ${ }^{2}$ Interdisciplinary Centre for Advanced Materials Simulation (ICAMS), Ruhr-Universität Bochum, D-44780 Bochum, Germany \\ ${ }^{3}$ Sandvik Coromant, 12680 Stockholm, Sweden
}

(Received 12 December 2019; accepted 6 March 2020; published 23 March 2020)

\begin{abstract}
$A b$ initio-calculated ideal strength and toughness describe the upper limits for mechanical properties attainable in real systems and can, therefore, be used in selection criteria for materials design. We employ density-functional $a b$ initio molecular dynamics (AIMD) to investigate the mechanical properties of defect-free rocksalt-structure (B1) TiN and $\mathrm{B} 1 \mathrm{Ti}_{1-x} \mathrm{Al}_{x} \mathrm{~N}(x=0.25,0.5,0.75)$ solid solutions subject to [001], [110], and [111] tensile deformation at room temperature. We determine the alloys' ideal strength and toughness, elastic responses, and ability to plastically deform up to fracture as a function of the Al content. Overall, TiN exhibits greater ideal moduli of resilience and tensile strengths than $(\mathrm{Ti}, \mathrm{Al}) \mathrm{N}$ solid solutions. Nevertheless, AIMD modeling shows that, irrespective of the strain direction, the binary compound systematically fractures by brittle cleavage at its yield point. The simulations also indicate that $\mathrm{Ti}_{0.5} \mathrm{Al}_{0.5} \mathrm{~N}$ and $\mathrm{Ti}_{0.25} \mathrm{Al}_{0.75} \mathrm{~N}$ solid solutions are inherently more resistant to fracture and possess much greater toughness than TiN due to the activation of local structural transformations (primarily of $\mathrm{B} 1 \rightarrow$ wurtzite type) beyond the elastic-response regime. In sharp contrast, (Ti,Al)N alloys with $25 \% \mathrm{Al}$ exhibit similar brittleness as TiN. The results of this work are examples of the limitations of elasticity-based criteria for prediction of strength, brittleness, ductility, and toughness in materials able to undergo phase transitions with loading. Comparing present and previous findings, we suggest a general principle for design of hard ceramic solid solutions that are thermodynamically inclined to dissipate extreme mechanical stresses via transformation toughening mechanisms.
\end{abstract}

DOI: 10.1103/PhysRevMaterials.4.033605

\section{INTRODUCTION}

Hard, refractory rocksalt-structure (B1) titanium aluminum nitride [(Ti,Al)N] ceramics are extensively applied as wear and oxidation resistant protective coatings on cutting tools and engine components $[1,2]$. The $(\mathrm{Ti}, \mathrm{Al}) \mathrm{N}$ parent binary phases-cubic rocksalt (B1) TiN and hexagonal wurtzite (B4) AlN-are immiscible at ambient conditions [3,4]. Nevertheless, far-from-equilibrium synthesis methods as, e.g., vapor deposition techniques [5], allow the kinetic stabilization of single-phase $\mathrm{B} 1 \mathrm{Ti}_{1-x} \mathrm{Al}_{x} \mathrm{~N}$ over wide metal compositional ranges (up to $x \approx 0.9$ ) [6,7]. During high-temperature operation $(\approx 1000-1200 \mathrm{~K}), \mathrm{B} 1(\mathrm{Ti}, \mathrm{Al}) \mathrm{N}$ alloys undergo spinodal decomposition into strained, coherent B1 AlN-rich / B1 TiNrich domains. This, in turn, greatly enhances the material's hardness thus improving the performance of the coating [8].

Although single-phase materials generally become softer with temperature $[9,10]$, alloys such as $(\mathrm{Ti}, \mathrm{Al}) \mathrm{N}$ are of considerable technological importance due to the spinodally induced

\footnotetext{
*Corresponding author: davide.sangiovanni@liu.se
}

Published by the American Physical Society under the terms of the Creative Commons Attribution 4.0 International license. Further distribution of this work must maintain attribution to the author(s) and the published article's title, journal citation, and DOI. Funded by Bibsam. age hardening effect. Over the past decades, several studies [8,11-18] focused on understanding the surface reactivity and thermodynamics of phase segregation in order to design (Ti,Al)N-based coatings with superior thermal stability and hinder $\mathrm{B} 1 \rightarrow \mathrm{B} 4 \mathrm{AlN}$-domain transformations [19-21]. In contrast, the toughness and resistance to fracture of (Ti,Al)N and $(\mathrm{Ti}, \mathrm{Al}) \mathrm{N}$-based solid solutions have not been investigated as extensively, with a few studies available in the literature [22-25]. Recent experiments suggest that, although detrimental for the alloy hardness, the nucleation of wurtzite phases in B1 AlN-rich regions does not affect, or is even beneficial for, the coating toughness by inhibiting crack formation and/or propagation [26,27]. Nonetheless, the presence of grain boundaries and voids, which act as weakest links [28] in polycrystalline samples, ultimately controls the resistance to fracture of $(\mathrm{Ti}, \mathrm{Al}) \mathrm{N}$, thus preventing the possibility of describing the alloy mechanical response as a function of metal composition. Moreover, the fact that $(\mathrm{Ti}, \mathrm{Al}) \mathrm{N}$ ceramics are typically synthesized in the form of thin films complicates the experimental evaluation of their strength and toughness. These problems render first-principles approaches an indispensable tool for the investigation of the mechanical properties of single-crystal B1 (Ti,Al)N solid solutions.

As a first step toward understanding the intrinsic ability of defect-free $\mathrm{B} 1 \mathrm{Ti}_{1-x} \mathrm{Al}_{x} \mathrm{~N}$ to withstand loading and plastically deform, we employ $a b$ initio molecular dynamics (AIMD) simulations at $300 \mathrm{~K}$-temperature at which refractory ceramics are typically brittle [29-31] - to investigate the effects 
induced by an increasing $\mathrm{Al}$ content $(x=0,0.25,0.5,0.75)$ on the alloys' responses to [001], [110], and [111] tensile deformation [32]. The simulations allow us to observe the dynamics of brittle cleavage vs lattice-transformation-induced toughening as a function of the metal composition.

\section{COMPUTATIONAL METHODS}

AIMD [33] simulations are performed using VASP [34-36] implemented with the projector augmented wave method [37]. The electronic exchange and correlation energies are parameterized according to the generalized gradient approximation of Perdew, Burke, and Ernzerhof [38]. All AIMD simulations employ $\Gamma$-point sampling of the reciprocal space and planewave cutoff energies of $300 \mathrm{eV}$. The nuclear equations of motion are integrated at 1-fs time steps, using an energy convergence criterion of $10^{-5} \mathrm{eV} /$ supercell for the ionic iterations. Prior to modeling tensile deformation, the supercell structural parameters are evaluated via NPT sampling of the configurational space (Parrinello-Rahman barostat [39] and Langevin thermostat set to $300 \mathrm{~K}$ ). Subsequently, AIMD within the $N V T$ ensemble (Nose-Hoover thermostat, with a Nose mass of $40 \mathrm{fs}$ ) is used to equilibrate the structures at $300 \mathrm{~K}$ during three additional ps, ensuring that the time-averaged stress components $\left|\sigma_{\mathrm{xx}}\right|,\left|\sigma_{\mathrm{yy}}\right|$, and $\left|\sigma_{\mathrm{zz}}\right|$ are $\leqslant 0.3 \mathrm{GPa}$.

In order to model tensile deformation, as well as shear deformation leading to lattice slip (results presented in a parallel study [40]), the $\mathrm{Ti}_{1-x} \mathrm{Al}_{x} \mathrm{~N}$ supercells are conveniently oriented with their $z$ vertical axis along the [001]-, [110]-, and [111] directions, and with lateral $x$ axes along the [1-10] Burgers vector direction (Fig. 1). [h $k l]$-oriented supercells are denoted below as $\operatorname{Ti}_{1-x} \mathrm{Al}_{x} \mathrm{~N}(h k l)$, where $h, k$, and $l$ are Miller indexes. $\mathrm{B} 1 \mathrm{Ti}_{1-x} \mathrm{Al}_{x} \mathrm{~N}(0 \leqslant x \leqslant 0.75)$ simulation boxes contain 288 metal and 288 nitrogen atoms (576 ideal B1 sites with 24 atomic layers orthogonal to the tensile strain $z$ direction), applying periodic boundary conditions in three dimensions (Fig. 1). Al and $\mathrm{Ti}$ atoms are stochastically arranged on the cation sublattice, thus ensuring negligible degrees of short-range metal ordering. Tensile deformation is carried out by following the scheme detailed in Ref. [32]. Briefly, at each strain step (2\% of the supercell length along $z$ ), the structures are (i) first rapidly equilibrated by isokinetic velocity rescaling during $300 \mathrm{fs}$ and (ii) then maintained at the same temperature during additional $2.7 \mathrm{ps}$ using the NoseHoover thermostat. At each strain step, tensile $\sigma_{\mathrm{zz}}$ stresses are determined by averaging $\sigma_{\mathrm{zz}}$ stresses calculated for the 500 final AIMD configurations. Moduli of ideal tensile resilience $U_{\mathrm{R}}$, energy density accumulated during elastic deformation (i.e., up to the yield point), and ideal tensile toughness $U_{\mathrm{T}}$, energy density absorbed up to fracture, are calculated by integrating the area underlying stress vs strain curves up to the yield $\delta_{y}$ and fracture $\delta_{f}$ strains, respectively. The supercell size along the lateral $x$ and $y$ directions is maintained unvaried during tensile deformation. Images and videos are generated using the visual molecular dynamics [41] software.

\section{RESULTS AND DISCUSSION}

Figure 2 illustrates the dependence of $\sigma_{z z}$ stresses vs uniaxial elongation of $\mathrm{B} 1 \mathrm{Ti}_{1-x} \mathrm{Al}_{x} \mathrm{~N}$ solid solutions determined via
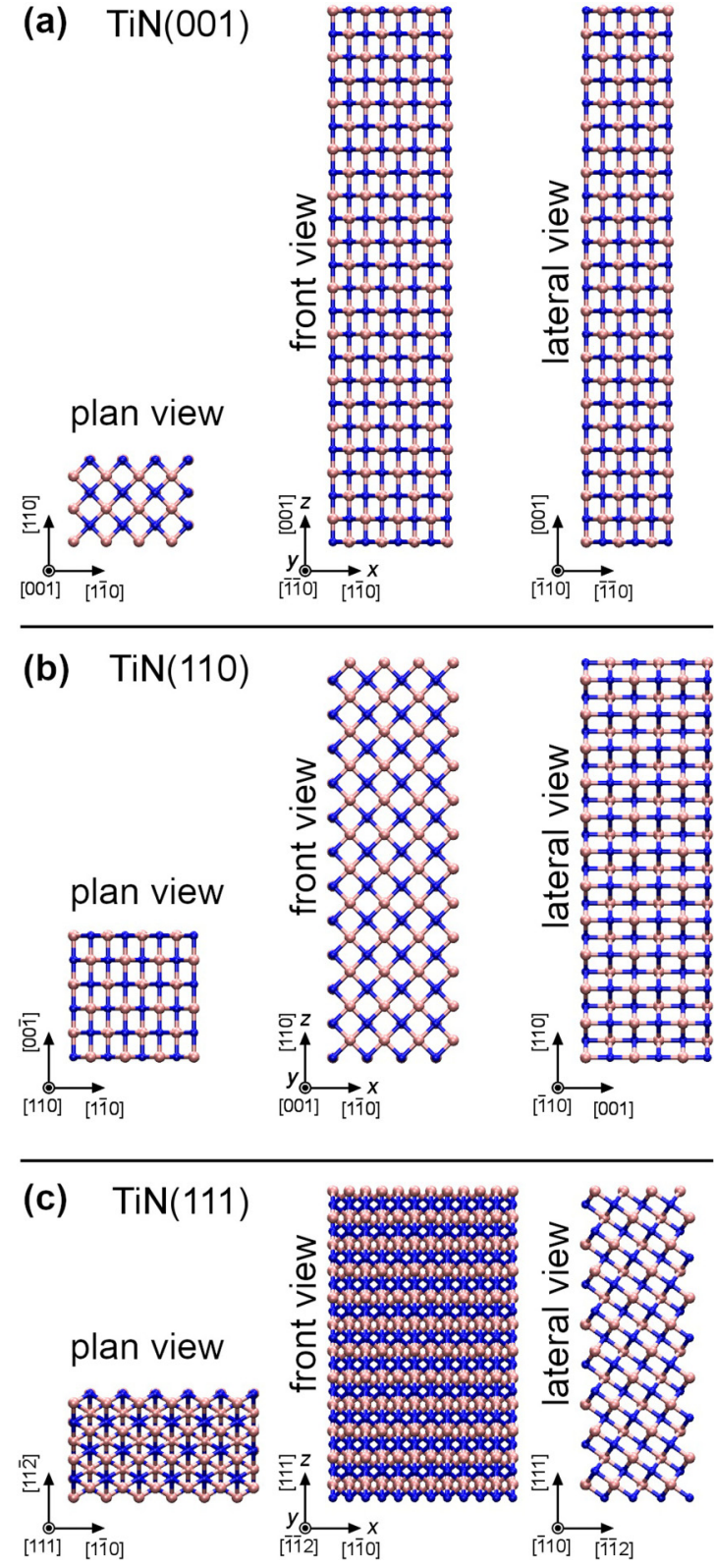

FIG. 1. Orthographic view of B1 supercell structures with (a) [001], (b) [110], and (c) [111] vertical (z) orientation used for AIMD tensile and shear deformation. The cation sublattice is formed of one metal species (pink spheres), while the anion sublattice is represented with blue spheres. In AIMD simulations, uniform tensile deformation is applied along vertical $(z)$ directions.

AIMD simulations at room temperature. The slopes of stress vs [001]-strain curves [42] within the alloy elastic-response up to $\delta=4 \%$ are used to calculate (see Eqs. (2) and (4) in Ref. [43]) the $C_{11}$ and $C_{12}$ elastic constants as a function of $x$. AIMD results yield $C_{11}$ elastic stiffnesses which, for $x$ increasing from 0 to 0.75 , monotonically decrease from $650 \pm 50 \mathrm{GPa}$ to $528 \pm 38 \mathrm{GPa}$ (Table I). Noting that $x$ and $y$ supercell axes are parallel to $\langle 110\rangle$ crystallographic directions [Fig. 1(a)], the $C_{12}$ elastic constant can be evaluated via $45^{\circ}$ rotation of the stress tensor within the $x y$ plane. The calculated $C_{12}$ values monotonically increase with the $\mathrm{Al}$ content from $128 \pm 6 \mathrm{GPa}$ (for $x=0$ ) to $174 \pm 8 \mathrm{GPa}$ 


\section{$\operatorname{TiN} \ominus \mathrm{Ti}_{0.75} \mathrm{Al}_{0.25} \mathrm{~N} \square \mathrm{Ti}_{0.50} \mathrm{Al}_{0.50} \mathrm{~N} \triangle \mathrm{Ti}_{0.25} \mathrm{Al}_{0.75} \mathrm{~N} \ominus$}
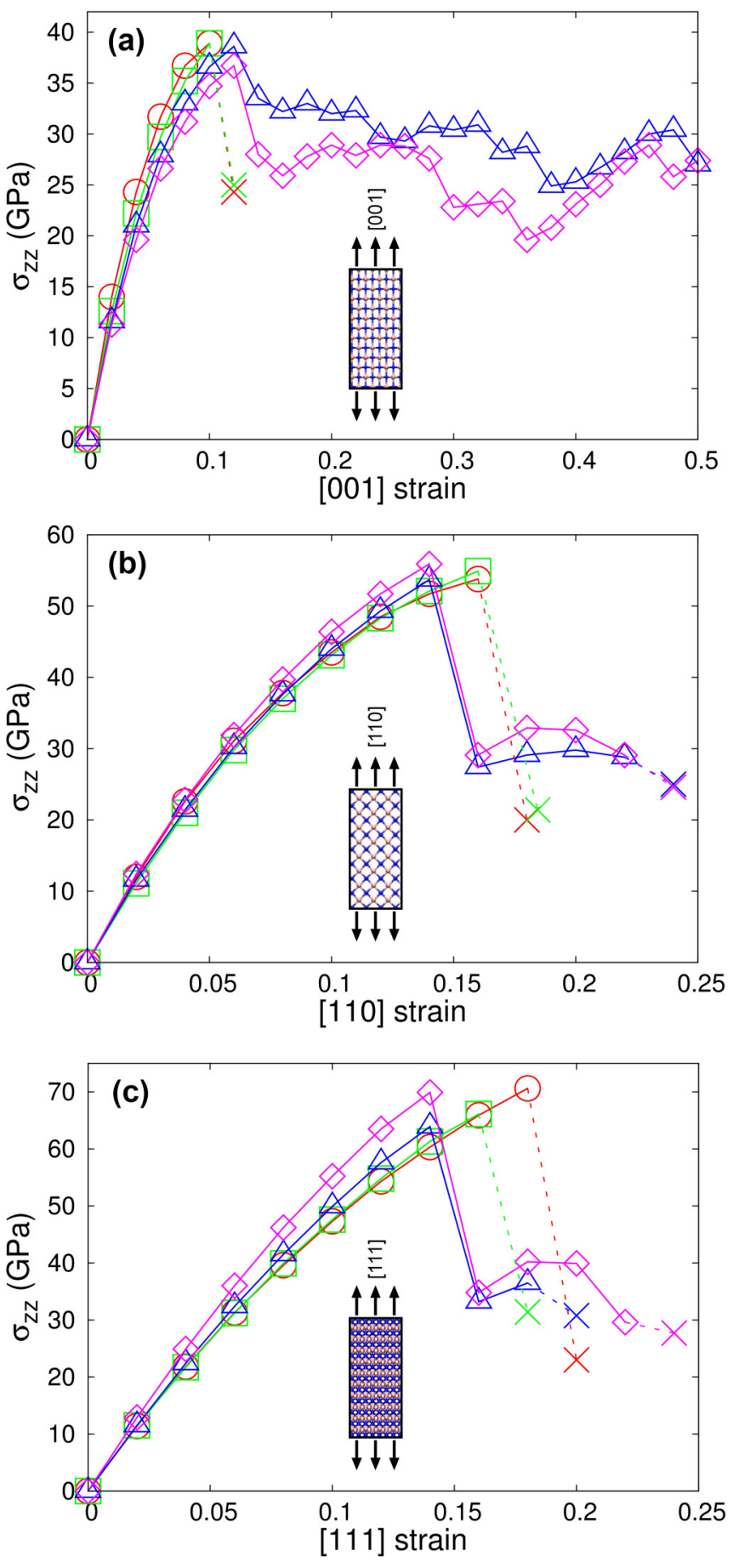

FIG. 2. $\mathrm{Ti}_{1-x} \mathrm{Al}_{x} \mathrm{~N}(001)$ stress/strain curves determined via AIMD simulations at $300 \mathrm{~K}$ for tensile deformation along (a) [001], (b) [110], and (c) [111] crystallographic directions. Brittle fracture conditions are indicated by dashed curves terminated with " $x$ " symbols. The insets are schematic representations of tensile-strained simulation supercells.

(for $x=0.75$ ). Accordingly, the bulk moduli $B$ remain approximately constant, or exhibit slight reductions with $\mathrm{Al}$ substitutions (Table I). The uncertainties on the $C_{11}$ and $C_{12}$ values arise from the sensitivity of calculated elastic constants
TABLE I. Room-temperature $C_{11}, C_{12}$ elastic constants and bulk moduli $B$ of $\mathrm{B} 1 \mathrm{Ti}_{1-x} \mathrm{Al}_{x} \mathrm{~N}(0 \leqslant x \leqslant 0.75)$ solid solutions obtained from the elastic mechanical-response regime determined during AIMD tensile elongation.

\begin{tabular}{lllll}
\hline \hline & \multicolumn{1}{c}{$\mathrm{TiN}$} & $\mathrm{Ti}_{0.75} \mathrm{Al}_{0.25} \mathrm{~N}$ & $\mathrm{Ti}_{0.5} \mathrm{Al}_{0.5} \mathrm{~N}$ & $\mathrm{Ti}_{0.25} \mathrm{Al}_{0.75} \mathrm{~N}$ \\
\hline$C_{11}(\mathrm{GPa})$ & $650 \pm 50$ & $592 \pm 38$ & $552 \pm 28$ & $528 \pm 38$ \\
$C_{12}(\mathrm{GPa})$ & $128 \pm 6$ & $153 \pm 7$ & $159 \pm 3$ & $174 \pm 8$ \\
$B(\mathrm{GPa})$ & $302 \pm 17$ & $300 \pm 13$ & $290 \pm 9$ & $292 \pm 13$ \\
\hline \hline
\end{tabular}

on the choice of strain ranges and deformation tensors [44] and the presence of small residual stress components in the relaxed supercell structures. The influence of metal-species arrangements, which produces a large scatter on $C_{11}$ and $C_{12}$ values calculated for anharmonic transition-metal nitride alloys [45], is expected to have negligible effects on the elastic response of $\mathrm{TiN}$ and $(\mathrm{Ti}, \mathrm{Al}) \mathrm{N}$ solid solutions. The trends in, and absolute values of $C_{11}, C_{12}$, and $B$ vs $x$ (Table I) agree, within uncertainty ranges, with those reported by previous $a b$ initio calculations at $0 \mathrm{~K}[46,47]$ and AIMD simulations at room temperature $[43,48]$.

Figure 2(a) and Table II show that the ideal $\mathrm{Ti}_{1-x} \mathrm{Al}_{x} \mathrm{~N}(001)$ tensile strength $\gamma^{[001]}$ - the vertical $\sigma_{z z}$ maximum stress obtained at the yield point during [001] elongation-remains approximately constant at $39 \mathrm{GPa}$ for $\mathrm{Al}$ contents in the range $0 \leqslant x \leqslant 0.5$. An increase in $\mathrm{Al}$ metal content to $75 \%$ induces a slight $\gamma^{[001]}$ reduction to $37 \mathrm{GPa}$. The yield points of $\mathrm{TiN}(001)$ and $\mathrm{Ti}_{0.75} \mathrm{Al}_{0.25} \mathrm{~N}(001)$ are reached at $10 \%$ elongation, while slightly larger values $(12 \%)$ are obtained for $\mathrm{Ti}_{0.5} \mathrm{Al}_{0.5} \mathrm{~N}(001)$ and $\mathrm{Ti}_{0.25} \mathrm{Al}_{0.75} \mathrm{~N}(001)$. Conversely to the trend observed for the $C_{11}$ elastic constants, which demonstrates a reduction in [001] stiffness for increasing $x$ [Fig. 2(a) and Table I], the alloys with high $\mathrm{Al}$ contents display larger moduli of resilience $\left(U_{\mathrm{R}}{ }^{[001]}=3.0\right.$ and $\left.2.8 \mathrm{GPa}\right)$ than $\operatorname{TiN}\left(U_{R}{ }^{[001]}=2.5 \mathrm{GPa}\right)$ and $\mathrm{Ti}_{0.75} \mathrm{Al}_{0.25} \mathrm{~N}\left(U_{R}{ }^{[001]}=2.4 \mathrm{GPa}\right)$, see Table II. To summarize, AIMD simulations demonstrate that the room-temperature $\mathrm{Ti}_{1-x} \mathrm{Al}_{x} \mathrm{~N}$ mechanical response to [001] tensile deformation up to yield points, which approximate the limit for the elastic response, is not dramatically affected by $\mathrm{Al}$ substitutions. This is consistent with the fact that covalent $\mathrm{N}(p)$-metal $\left(d-e_{\mathrm{g}}\right)$ bonding states remain fully occupied even though the valence electron concentration of $\mathrm{B} 1 \mathrm{Ti}_{1-x} \mathrm{Al}_{x} \mathrm{~N}$ solid solutions decreases from $9 \mathrm{e}^{-} /$f.u. (for TiN) to $8.25 \mathrm{e}^{-} /$f.u. (for $\mathrm{Ti}_{0.25} \mathrm{Al}_{0.75} \mathrm{~N}$ ) [49-51]. Nonetheless, simulation results (see below) suggest that an increasing Al content significantly promotes the alloys' ability to plastically deform, thus improving the material's toughness.

In agreement with AIMD results of Refs. [32,52], an extension of $\mathrm{TiN}(001)$ beyond its tensile yield point $(\approx 10 \%)$ leads to brittle fracture of the material. AIMD modeling reveals that $25 \%$ replacement of $\mathrm{Ti}$ atoms with $\mathrm{Al}$ induces negligible effects on the alloy plastic response to [001] uniaxial deformation; cubic $\mathrm{Ti}_{0.75} \mathrm{Al}_{0.25} \mathrm{~N}(001)$ solid solutions remain brittle and undergo sudden cleavage on the (001) plane at strains larger than 10\% [see Figs. 2(a), 3, and Table II). In sharp contrast, $\mathrm{Ti}_{1-x} \mathrm{Al}_{x} \mathrm{~N}$ alloys with $\mathrm{Al}$ contents $x \geqslant 0.5$ are considerably more resistant to fracture than $\mathrm{TiN}$ and $\mathrm{Ti}_{0.75} \mathrm{Al}_{0.25} \mathrm{~N}$. 
TABLE II. Mechanical properties and behavior of $\mathrm{B} 1 \mathrm{Ti}_{1-x} \mathrm{Al}_{x} \mathrm{~N}(0 \leqslant x \leqslant 0.75)$ solid solutions as predicted via AIMD simulations at $300 \mathrm{~K}$. The symbols represent: $\gamma=$ ideal tensile strength, $U_{\mathrm{R}}=$ modulus of resilience, $U_{\mathrm{T}}=$ tensile toughness, $\delta_{\mathrm{y}}=$ yield strain, $\delta_{\mathrm{f}}=$ elongation at fracture.

\begin{tabular}{|c|c|c|c|c|}
\hline Tensile strain direction & TiN & $\mathrm{Ti}_{0.75} \mathrm{Al}_{0.25} \mathrm{~N}$ & $\mathrm{Ti}_{0.5} \mathrm{Al}_{0.5} \mathrm{~N}$ & $\mathrm{Ti}_{0.25} \mathrm{Al}_{0.75} \mathrm{~N}$ \\
\hline \multicolumn{5}{|l|}{ [001] } \\
\hline$\gamma(\mathrm{GPa})$ & 39 & 39 & 39 & 37 \\
\hline$U_{\mathrm{R}}(\mathrm{GPa})$ & 2.5 & 2.4 & 3.0 & 2.8 \\
\hline$\delta_{y}(\%)$ & 10 & 10 & 12 & 12 \\
\hline$U_{\mathrm{T}}(\mathrm{GPa})$ & $\approx U_{\mathrm{R}}$ & $\approx U_{\mathrm{R}}$ & $\gg U_{\mathrm{R}}$ & $\gg U_{\mathrm{R}}$ \\
\hline$\delta_{f}(\%)$ & 12 & 12 & $\approx 50$ & $\approx 50$ \\
\hline Deformation mechanism & Elastic & Elastic & Elastic $\rightarrow$ transformation toughening & Elastic $\rightarrow$ transformation toughening \\
\hline Failure mechanism & Sudden cleavage & Sudden cleavage & Slow bond fraying & Slow bond fraying \\
\hline Mechanical behavior & Hard/brittle & Hard/brittle & Hard/supertough & Hard/supertough \\
\hline \multicolumn{5}{|l|}{ [110] } \\
\hline$\gamma(\mathrm{GPa})$ & 54 & 55 & 54 & 56 \\
\hline$U_{\mathrm{R}}(\mathrm{GPa})$ & 5.5 & 5.4 & 4.4 & 4.7 \\
\hline$\delta_{y}(\%)$ & 16 & 16 & 14 & 14 \\
\hline$U_{\mathrm{T}}(\mathrm{GPa})$ & $\approx U_{\mathrm{R}}$ & $\approx U_{\mathrm{R}}$ & $\approx(3 / 2) \cdot U_{R}$ & $\approx(3 / 2) \cdot U_{R}$ \\
\hline$\delta_{f}(\%)$ & 18 & 18 & $\approx 24$ & $\approx 24$ \\
\hline Deformation mechanism & Elastic & Elastic & Elastic $\rightarrow$ transformation toughening & Elastic $\rightarrow$ transformation toughening \\
\hline Failure mechanism & Sudden cleavage & Sudden cleavage & Bond fraying & Bond fraying \\
\hline Mechanical behavior & Hard/brittle & Hard/brittle & Hard/tough & Hard/tough \\
\hline \multicolumn{5}{|l|}{ [111] } \\
\hline$\gamma(\mathrm{GPa})$ & 71 & 66 & 64 & 70 \\
\hline$U_{\mathrm{R}}(\mathrm{GPa})$ & 7.3 & 6.0 & 4.9 & 5.5 \\
\hline$\delta_{y}(\%)$ & 18 & 16 & 14 & 14 \\
\hline$U_{\mathrm{T}}(\mathrm{GPa})$ & $\approx U_{\mathrm{R}}$ & $\approx U_{\mathrm{R}}$ & $\gtrsim U_{R}$ & $\approx(3 / 2) \cdot U_{R}$ \\
\hline$\delta_{f}(\%)$ & 20 & 18 & $\approx 20$ & $\approx 24$ \\
\hline Deformation mechanism & Elastic & Elastic & Elastic & Elastic $\rightarrow$ transformation toughening \\
\hline Failure mechanism & Sudden cleavage & Sudden cleavage & Rapid bond fraying & Bond fraying \\
\hline Mechanical behavior & Hard/brittle & Hard/brittle & Hard/partially tough & Hard/tough \\
\hline
\end{tabular}

This is due to their ability to undergo local structural changes into wurtzite-like atomic environments when the elongation overcomes their yield points [see Figs. 2(a), 4, and 5].

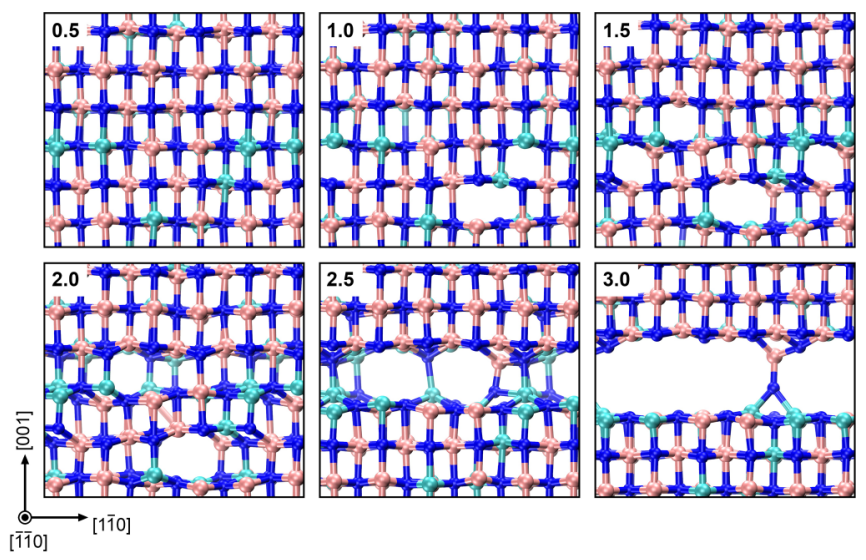

FIG. 3. Cleavage of $\mathrm{B} 1 \mathrm{Ti}_{0.75} \mathrm{Al}_{0.25} \mathrm{~N}(001)$ on the (001) plane due to [001] tensile deformation of $12 \%$. The AIMD simulation time passed since the alloy has been extended by $12 \%$ is in units of ps (see upper-left corners in each panel). Color legend for atomic species: blue $=\mathrm{N}$, pink $=\mathrm{Ti}$, cyan $=\mathrm{Al}$. The dynamics bonds have cutoff lengths of $2.6 \AA$.
The modifications in the bonding network that become operative in $\mathrm{B} 1 \mathrm{Ti}_{0.5} \mathrm{Al}_{0.5} \mathrm{~N}(001)$ and $\mathrm{Ti}_{0.25} \mathrm{Al}_{0.75} \mathrm{~N}(001)$ solid solutions at high tensile strains can be rationalized on the basis of transformation pathways induced by pressure in wurtzite group-III nitrides, such as AlN (see examples of strain-mediated B4 $\rightarrow$ B1 AlN transitions in Ref. [53]), which is a border $(x=1)$ case for the investigated $\mathrm{Ti}_{1-x} \mathrm{Al}_{x} \mathrm{~N}$ system [54,55]. Tetragonal [56] and hexagonal (graphiticlike, boronnitride prototype, $\mathrm{B}_{\mathrm{k}}$ ) crystal structures are the predicted transition states along the B4 $\rightarrow$ B1 transformation path of group-III nitrides and other semiconductors (see, e.g., Fig. 1 in Ref. [57]). The B4 $\rightarrow$ B1 AlN transformation path energetically favors the $\mathrm{B}_{\mathrm{k}}$ intermediate state: compression of the wurtzite lattice along the [0001] direction followed by shear deformation within the (0001) $\mathrm{B}_{\mathrm{k}}$ plane [55]. It is therefore expected that the inverse $(\mathrm{B} 1 \rightarrow \mathrm{B} 4)$ AlN phase transition should also preferentially occur through the $B_{k}$ metastable configuration.

At deviance with the transformation path predicted for AlN, AIMD simulations show that $\mathrm{B} 1 \mathrm{Ti}_{0.5} \mathrm{Al}_{0.5} \mathrm{~N}(001)$ and B1 $\mathrm{Ti}_{0.25} \mathrm{Al}_{0.75} \mathrm{~N}(001)$ elongated beyond their yield point exhibit buckling of (001) atomic planes, which correspond to a tetragonal state (see schematic illustration in Fig. 6). The formation of tetragonal $(\mathrm{Ti}, \mathrm{Al}) \mathrm{N}$ domains that precede the appearance of wurtzite-like environments is reminiscent 

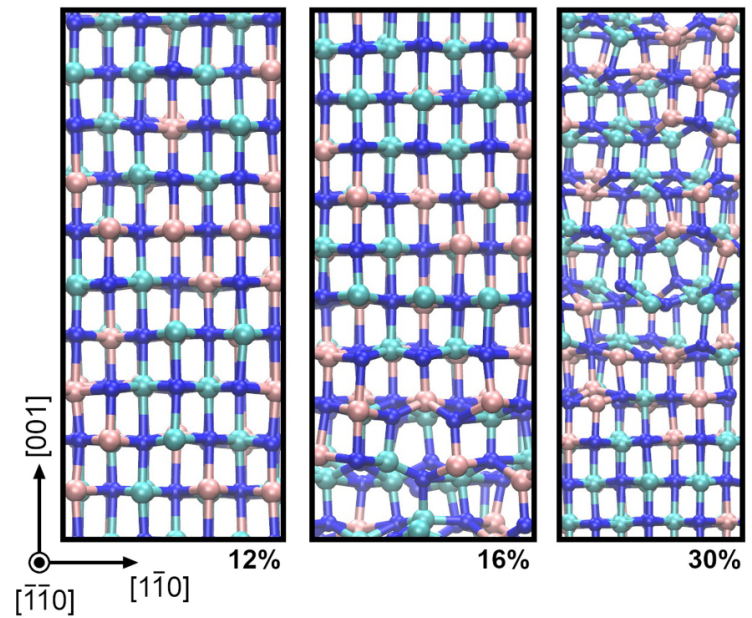

FIG. 4. Local B1 $\rightarrow$ B4 structural transitions in tensile-strained $\mathrm{Ti}_{0.50} \mathrm{Al}_{0.50} \mathrm{~N}(001)$. The three orthographic views are AIMD snapshots taken at elongations of (from left to right) $12 \%$ [which corresponds to the $\mathrm{Ti}_{0.50} \mathrm{Al}_{0.50} \mathrm{~N}(001)$ yield point in Fig. 2(a)], $16 \%$, and $30 \%$. The dynamics bonds have cutoff lengths of $2.6 \AA$. Color legend: blue $=\mathrm{N}$, pink $=\mathrm{Ti}$, cyan $=\mathrm{Al}$.

of the solid $\rightarrow$ solid transformation path predicted for other B4-structure crystals as, e.g., $\mathrm{GaN}$ and $\mathrm{ZnO}$ [56]. As indicated in Ref. [56], B4 $\rightarrow$ tetragonal $\rightarrow \mathrm{B} 1$ transitions are presumably favored due to the presence of $d$ electrons (note that $\mathrm{B} 1$ $\mathrm{Ti}_{1-x} \mathrm{Al}_{x} \mathrm{~N}$ with $0 \leqslant x \leqslant 0.75$ is a conductor with $d$ states at the Fermi level [58]). The lattice transformation active in $\mathrm{Ti}_{0.5} \mathrm{Al}_{0.5} \mathrm{~N}$ and $\mathrm{Ti}_{0.25} \mathrm{Al}_{0.75} \mathrm{~N}$ ultimately results in a considerably enhanced resistance to fracture and a substantially increased toughness (area underlying stress/strain curves) during [001] tensile deformation (see Table II).

Given that (001) surfaces in B1-structure ceramics have much lower formation energies than (110) and (111) terminations [59], i.e., crack formation is energetically favored on (001) planes, the AIMD results discussed above for $\mathrm{Ti}_{1-x} \mathrm{Al}_{x} \mathrm{~N}(001)$ tensile elongation are of major importance for assessing the $(\mathrm{Ti}, \mathrm{Al}) \mathrm{N}$ resistance to fracture as a function of the $\mathrm{Al}$ content. Nevertheless, complementary AIMD results obtained for crystals strained along [110] and [111] directions (see below) provide a more comprehensive understanding for the effects induced by $\mathrm{Al}$ on the inherent mechanical response of $\mathrm{B} 1 \mathrm{Ti}_{1-x} \mathrm{Al}_{x} \mathrm{~N}$ to elongation.

For an increasing $\mathrm{Al}$ concentration, tensile-strained $\mathrm{Ti}_{1-x} \mathrm{Al}_{x} \mathrm{~N}(110)$ and $\mathrm{Ti}_{1-x} \mathrm{Al}_{x} \mathrm{~N}(111)$ exhibit a monotonic increase in elastic stiffness (i.e., initial slope in $\sigma_{\mathrm{zz}}$ vs strain), accompanied by an overall reduction in $U_{\mathrm{R}}$, [see Figs. 2(b), 2(c), and Table II]. These trends are opposite to that calculated for $\mathrm{Ti}_{1-x} \mathrm{Al}_{x} \mathrm{~N}(001)$. In contrast, the $\gamma^{[110]}$ and $\gamma^{[111]}$ tensile strengths of the alloy are not significantly affected by $\mathrm{Al}$ substitutions. In fact, for each investigated strain direction, the relative strength variation with $x$ remains within $10 \%$ (Fig. 2 and Table II). Irrespective of the metal composition, AIMD results show that the relationship between alloy tensile strengths is $\gamma^{[111]}(64-71 \mathrm{GPa})>\gamma^{[110]}(54-56 \mathrm{GPa})>$ $\gamma^{[001]}(37-39 \mathrm{GPa})$. This is consistent with the trend in surface formation energies $E_{\mathrm{s}}{ }^{(111)}>E_{\mathrm{s}}{ }^{(110)}>E_{\mathrm{s}}{ }^{(001)}$ reported for B1structure materials [59], that is, the uniaxial strength is related
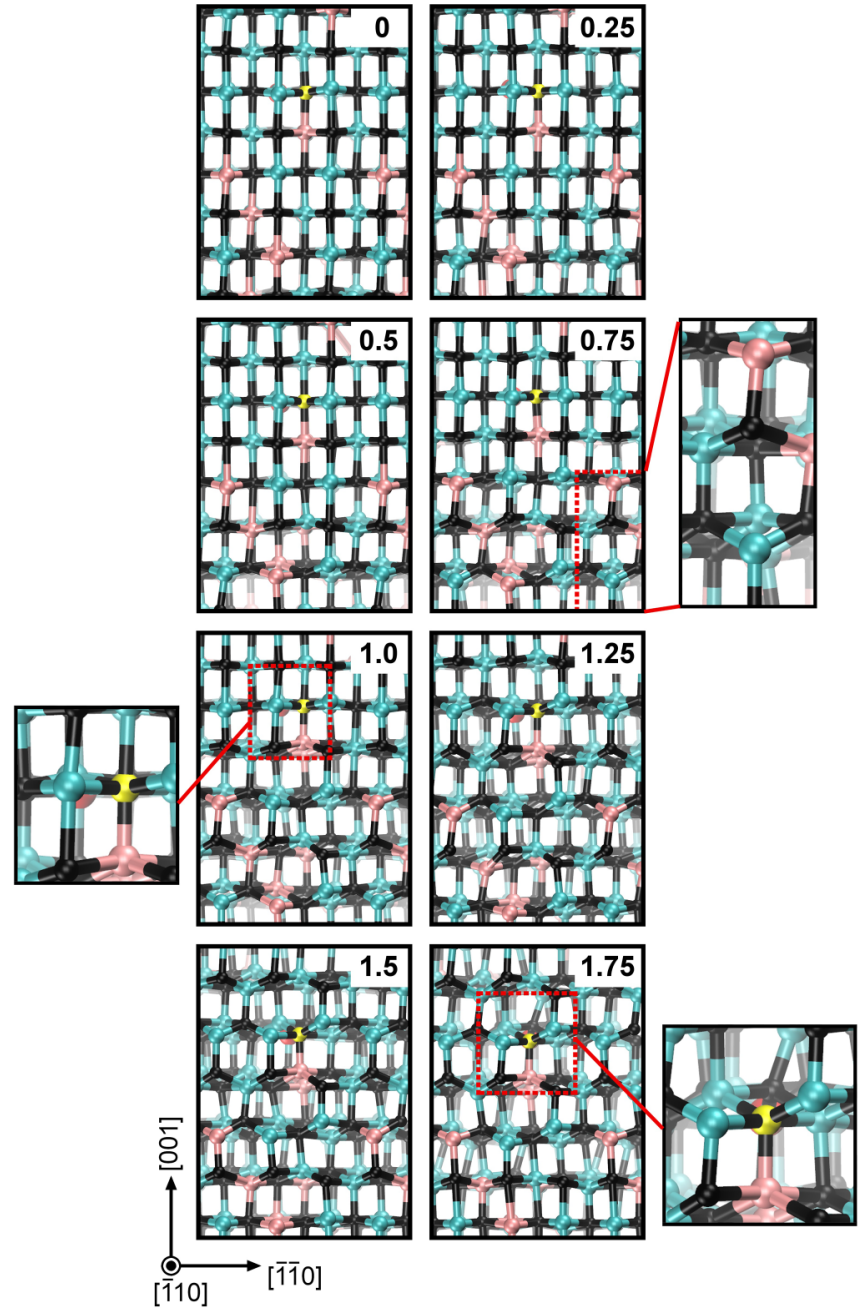

FIG. 5. Orthographic view of local $\mathrm{B} 1 \rightarrow$ tetragonal $\rightarrow \mathrm{B} 4$ structural transitions in $\mathrm{Ti}_{0.25} \mathrm{Al}_{0.75} \mathrm{~N}(001)$ elongated by $14 \%$. Each panel is labeled with the simulation time (ps). $\mathrm{N}$ atoms are colored in black, while Ti/Al atoms are pink/cyan spheres. The dynamics bonds have cutoff lengths of $2.6 \AA$. The magnification at 0.75 ps shows a local tetragonal (Ti,Al)N environment. The insets at 1.0 and $1.75 \mathrm{ps}$ facilitate visualization of local tetragonal $\rightarrow$ B4 transformations (schematically represented in Fig. 6), which proceed via lattice shearing within the (001) $x y$ plane: a $\mathrm{N}$ atom (yellow) and an $\mathrm{Al}$ atom (red) located on different $(-110)$ layers progressively align on a same direction, normal to the page.

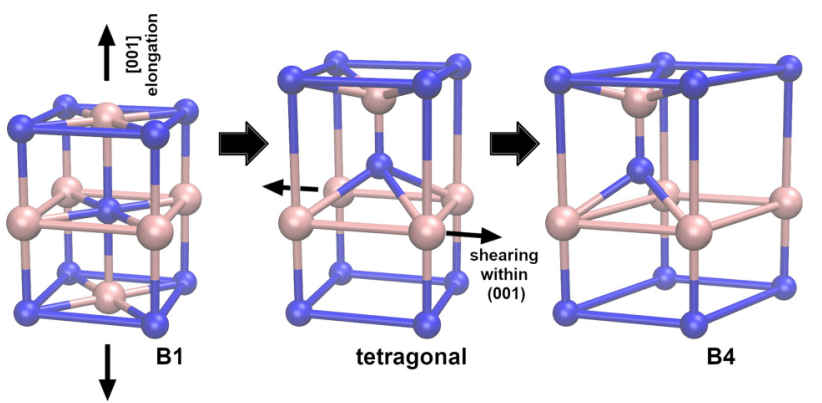

FIG. 6. Schematic representation of $\mathrm{B} 1 \rightarrow$ tetragonal $\rightarrow \mathrm{B} 4$ structural transitions induced by [001] tensile deformation. Spheres of different colors indicate metal and nonmetal atoms. 


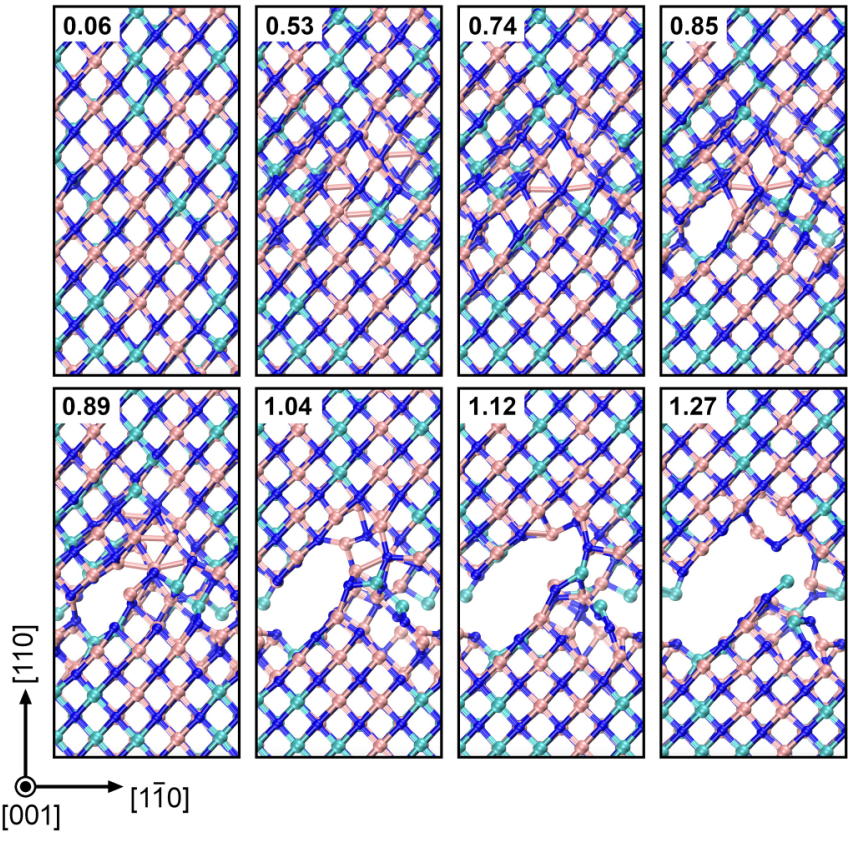

FIG. 7. AIMD snapshots of $\mathrm{Ti}_{0.75} \mathrm{Al}_{0.25} \mathrm{~N}(110)$ brittle cleavage dynamics taken over a time window of $\approx 1.3 \mathrm{ps}$ at a constant [110] tensile elongation of $18 \%$ [see green curve in Fig. 2(b)]. The time progression (ps) is indicated in the upper-left corner of each panel. Note that, although the strain is along [110], fracture develops on (001) crystallographic planes. The dynamics bonds have cutoff lengths of $2.6 \AA$. Color legend: blue $=\mathrm{N}$, pink $=\mathrm{Ti}$, cyan $=\mathrm{Al}$.

to the energy required to cleave the crystal on a plane normal to the elongation direction.

Although alloys with $\mathrm{Al}$ concentrations $\geqslant 50 \%$ present smaller $U_{\mathrm{R}}{ }^{[110]}$ and $U_{\mathrm{R}}{ }^{[111]}$ moduli of resilience than TiN and $\mathrm{Ti}_{0.75} \mathrm{Al}_{0.25} \mathrm{~N}$, as described below, AIMD simulations reveal that high $\mathrm{Al}$ contents are beneficial for the total tensile toughness $U_{\mathrm{T}}{ }^{[110]}$ and $U_{\mathrm{T}}{ }^{[111]}$ [see Figs. 2(b), 2(c), and Table II]. Combined with the results described above for [001]-strained materials, these findings indicate that the room-temperature mechanical properties of $\mathrm{B} 1 \mathrm{Ti}_{1-x} \mathrm{Al}_{x} \mathrm{~N}$ are considerably improved by $\mathrm{Al}$ substitutions of $\geqslant 50 \%$.

Consistent with AIMD results reported in a previous study [32,52], TiN(110) undergoes sudden brittle failure when the [110] uniaxial strain reaches $\approx 18 \%$ [Fig. 2(b)]. The mechanical response of $\mathrm{Ti}_{0.75} \mathrm{Al}_{0.25} \mathrm{~N}$ solid solutions to [110] elongation is nearly equivalent to that determined for the binary compound [Fig. 2(b)]. AIMD simulation snapshots of $\mathrm{Ti}_{0.75} \mathrm{Al}_{0.25} \mathrm{~N}(110)$ at a constant tensile strain of $18 \%$ display rapid (within $1.3 \mathrm{ps)}$ bond snapping that causes brittle cleavage of the alloy (Fig. 7). Note that the fractured region follows a zig-zag pattern on (001) crystallographic planes. Conversely, B1 solid solutions that contain $50 \%$ and $75 \%$ Al undergo, after the yield point, local changes in bonding geometries that prevent sudden mechanical failure [in comparison to TiN(110) and $\left.\mathrm{Ti}_{0.75} \mathrm{Al}_{0.25} \mathrm{~N}(110)\right]$. The transformation toughening effect induced by $\mathrm{Al}$ substitutions in [110]-strained $\mathrm{Ti}_{0.5} \mathrm{Al}_{0.5} \mathrm{~N}$ and $T_{0.25} \mathrm{Al}_{0.75} \mathrm{~N}$ is illustrated by AIMD snapshots in Figs. 8 and 9 , respectively.

As shown in Fig. 2(b), vertical $\sigma_{\text {zz }}$ stresses meet the ideal $\mathrm{Ti}_{0.5} \mathrm{Al}_{0.5} \mathrm{~N}(110)$ and $\mathrm{Ti}_{0.25} \mathrm{Al}_{0.75} \mathrm{~N}(110)$ tensile strengths for
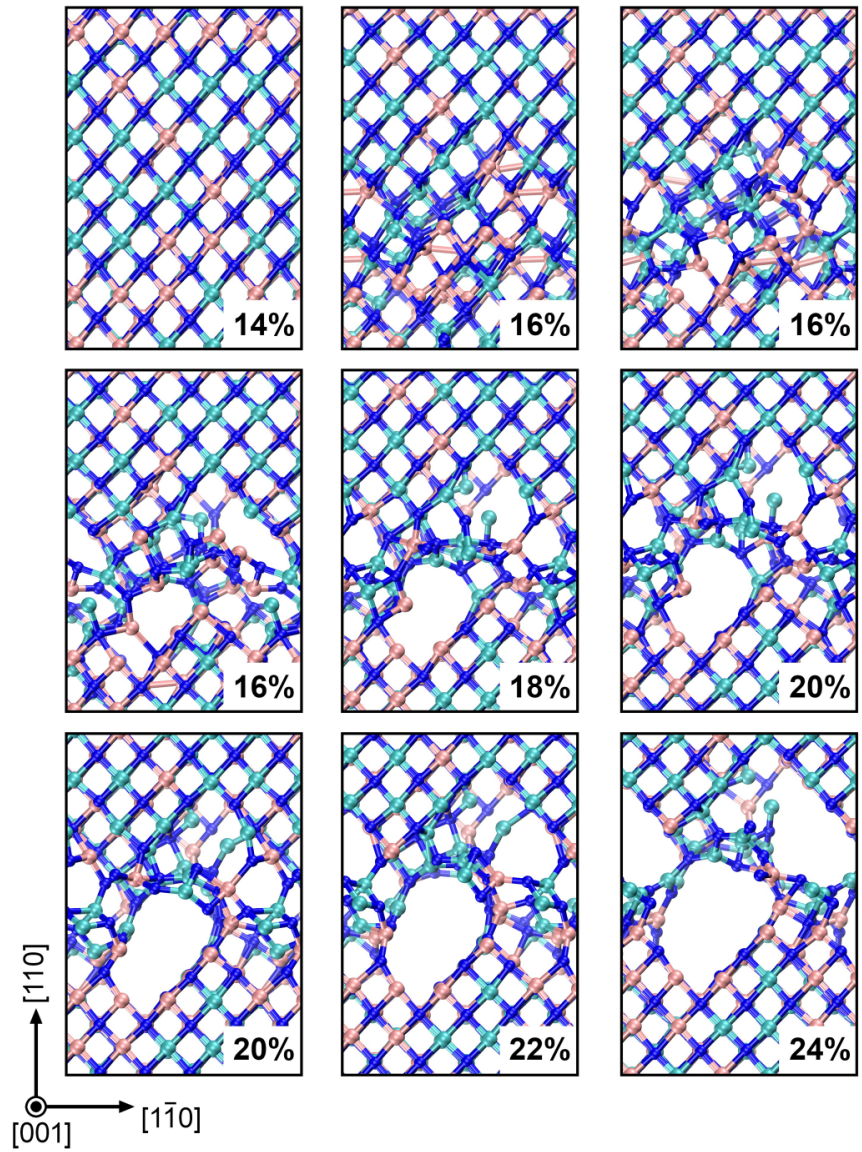

FIG. 8. AIMD snapshot sequence of $\mathrm{Ti}_{0.5} \mathrm{Al}_{0.5} \mathrm{~N}(110)$ tensilestrained from $14 \%$ [yield point, see Fig. 2(b)] up to $24 \%$. The three snapshots at $16 \%$ strain are taken at different simulation times during $\approx 1$ ps. The alloy fractures at $\approx 22-24 \%$ strain. Note that open surfaces form primarily on (001) planes. The dynamics bonds have cutoff lengths of $2.6 \AA$. Color legend: blue $=\mathrm{N}$, pink $=\mathrm{Ti}$, cyan $=\mathrm{Al}$.

an elongation of $14 \%$. Up to that strain, both alloys maintain ideal octahedral atomic coordination (see upper-left panels in Figs. 8 and 9). A [110] deformation of $16 \%$, activates local modifications in the bonding network (Figs. 8 and 9), as reflected by a drop in $\sigma_{\mathrm{zz}}$ vs strain in Fig. 2(b). Thus, the mechanical response beyond the yield points of $\mathrm{Ti}_{0.5} \mathrm{Al}_{0.5} \mathrm{~N}(110)$ and $\mathrm{Ti}_{0.25} \mathrm{Al}_{0.75} \mathrm{~N}(110)$ solid solutions is dramatically different to those observed for $\operatorname{TiN}(110)$ [32] and $\mathrm{Ti}_{0.75} \mathrm{Al}_{0.25} \mathrm{~N}(110)$. Fracture in $\mathrm{Ti}_{0.5} \mathrm{Al}_{0.5} \mathrm{~N}(110)$ and $\mathrm{Ti}_{0.25} \mathrm{Al}_{0.75} \mathrm{~N}(110)$ occurs in a more controlled manner. Relatively slow bond fraying accompanied by progressive void opening delays mechanical failure. In this regard, we should underline that, due to transformation toughening processes, the fracture points of $\mathrm{Ti}_{0.5} \mathrm{Al}_{0.5} \mathrm{~N}(110)$ and $\mathrm{Ti}_{0.25} \mathrm{Al}_{0.75} \mathrm{~N}(110)$ are not unambiguously identifiable. The AIMD bonding configurations hold the materials together up to $20 \%$ elongation, while rupture is identified by the appearance of several voids at $\approx 22-24 \%$ strain, see Figs. 8 and 9. More important, however, our results qualitatively demonstrate that relatively high $\mathrm{Al}$ contents in (Ti,Al)N lead to a superior resistance to fracture. 

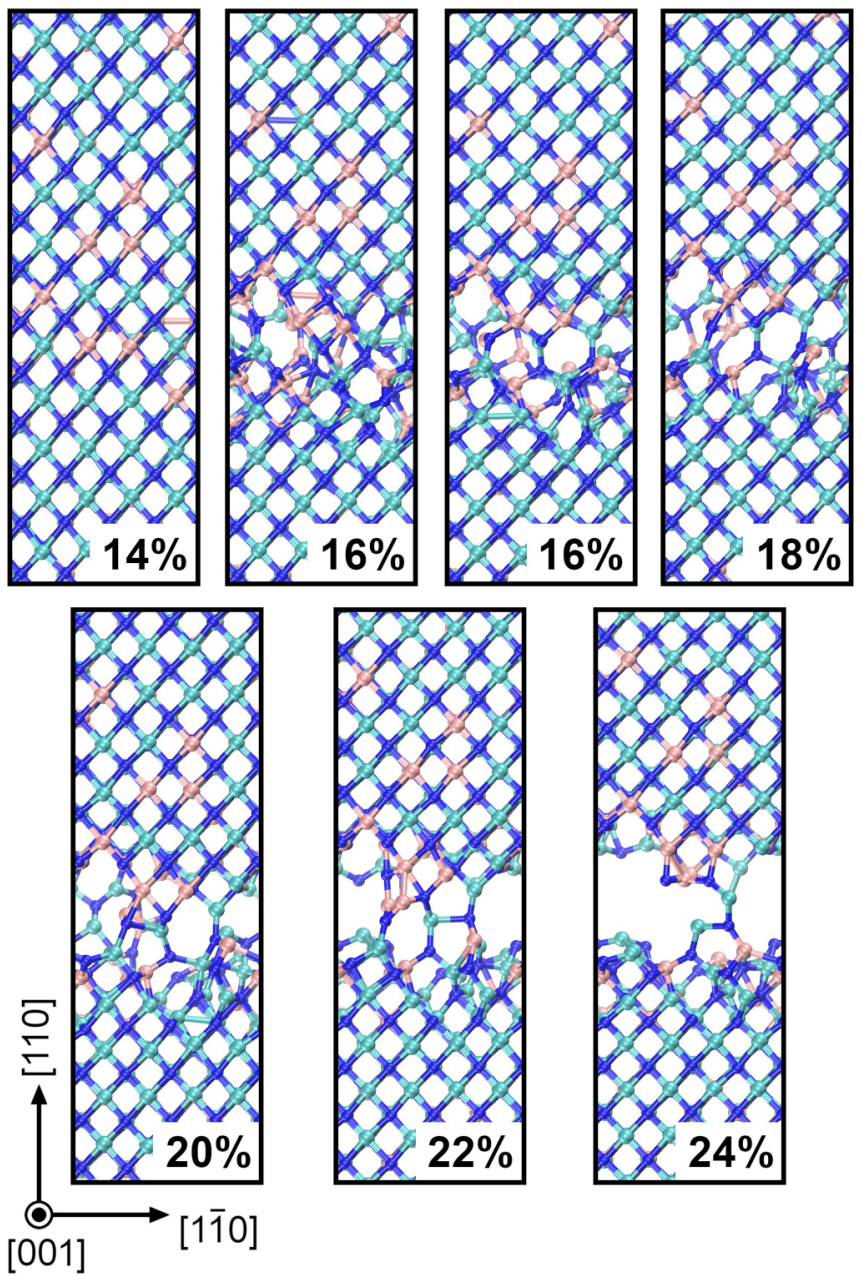

FIG. 9. AIMD snapshots of $\mathrm{Ti}_{0.25} \mathrm{Al}_{0.75} \mathrm{~N}(110)$ subject to uniaxial strains between $14 \%$ and $24 \%$. The two snapshots at $16 \%$ strain are taken at different simulation times. The alloy fracture occurs at $\approx 22-24 \%$ strain. Note that open surfaces form primarily on (001) planes. The dynamics bonds have cutoff lengths of $2.6 \AA$. Color legend: blue $=\mathrm{N}$, pink $=\mathrm{Ti}$, cyan $=\mathrm{Al}$.

Similarly to the results obtained for $\mathrm{B} 1 \mathrm{Ti}_{1-x} \mathrm{Al}_{x} \mathrm{~N}$ subject to [001] and [110] tensile strain, AIMD simulations of supercells deformed along [111] directions confirm that Al substitutions are beneficial for the alloy resistance to fracture. TiN(111) displays the highest $\gamma^{[111]}$ tensile strength (71 GPa) and resilience $U_{\mathrm{R}}{ }^{[111]}=7.3 \mathrm{GPa}$. As expected, the binary compound fractures in a brittle manner beyond its yield point [Figs. 2(c) and 10]. A constant elongation of $20 \%$ leads, within $1.8 \mathrm{ps}$, to bond snapping and crack opening primarily along (001) crystallographic planes. $\mathrm{Ti}_{0.75} \mathrm{Al}_{0.25} \mathrm{~N}(111)$ displays a mechanical response to [111] deformation qualitatively similar to that of the binary nitride, that is, brittle fracture occurs within few ps at constant strain of 18\%, Fig. 2(c). $\mathrm{Ti}_{0.5} \mathrm{Al}_{0.5} \mathrm{~N}(111)$ and $\mathrm{Ti}_{0.25} \mathrm{Al}_{0.75} \mathrm{~N}(111)$ solid solutions reach their yield points at $14 \%$ strain, Fig. 2(c), with all atoms maintaining octahedral coordination (upper-left panel in Fig. 11). As anticipated by the results determined for $\mathrm{Ti}_{0.5} \mathrm{Al}_{0.5} \mathrm{~N}$ and $\mathrm{Ti}_{0.25} \mathrm{Al}_{0.75} \mathrm{~N}$ alloys strained along the [001] and [110] directions, a [111] deformation beyond the yield point activates

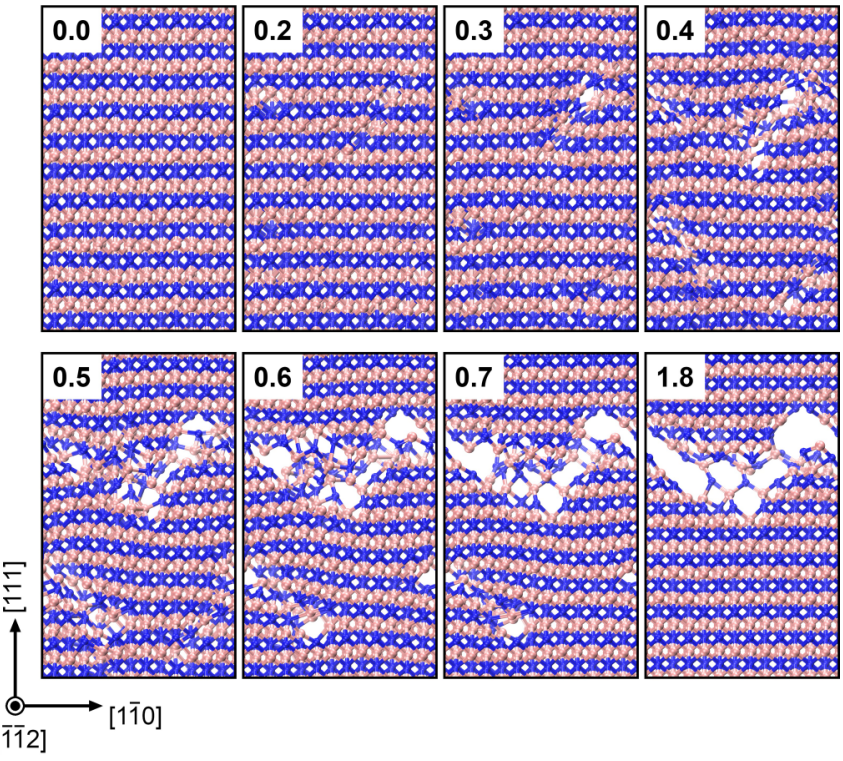

FIG. 10. AIMD snapshots of TiN(111) sudden breakage when maintained at a constant [111] elongation of $20 \%$. The numbers in each panel indicate time progression (ps). The dynamics bonds have cutoff lengths of $2.6 \AA$. Color legend: blue $=\mathrm{N}$, pink $=$ Ti.
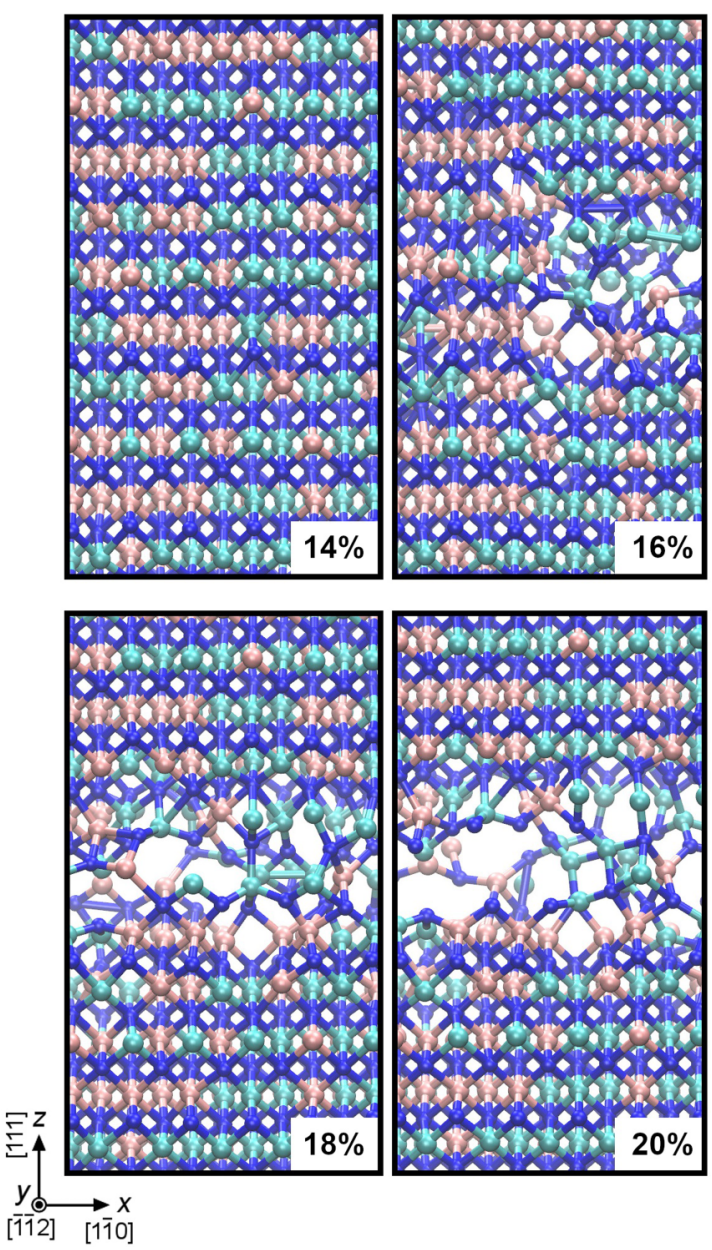

FIG. 11. AIMD snapshots of $\mathrm{Ti}_{0.5} \mathrm{Al}_{0.5} \mathrm{~N}(111)$ breakage during [111] tensile deformation. The dynamics bonds have cutoff lengths of $2.6 \AA$. Color legend: blue $=\mathrm{N}$, pink $=\mathrm{Ti}$, cyan $=\mathrm{Al}$. 

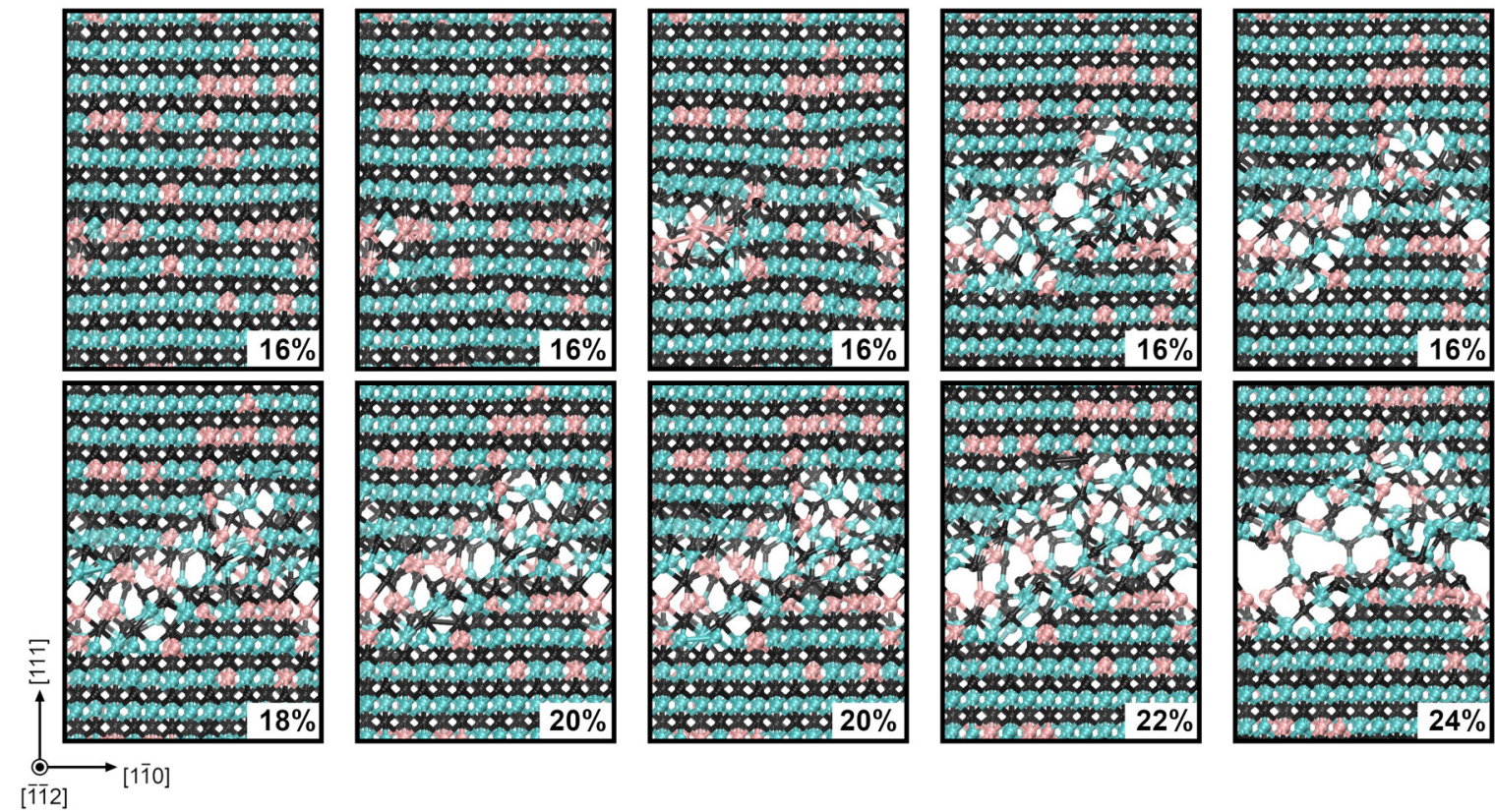

FIG. 12. AIMD snapshots of $\mathrm{Ti}_{0.25} \mathrm{Al}_{0.75} \mathrm{~N}(111)$ breakage during [111] tensile deformation. The upper panels (16\% deformation) show atomic configurations at different simulation times, during a timeframe of $\approx 1.5 \mathrm{ps} . \mathrm{N}$ atoms are colored in black, while Ti/Al atoms are pink/cyan spheres. The dynamics bonds have cutoff lengths of $2.6 \AA$.

local structural transformations, which allow stress dissipation and prevent brittle fracture. AIMD snapshots in Figs. 11 and 12 demonstrate that $\mathrm{Ti}_{0.5} \mathrm{Al}_{0.5} \mathrm{~N}$ and $\mathrm{Ti}_{0.25} \mathrm{Al}_{0.75} \mathrm{~N}$ break via a progressive, yet slow, reduction in bond densities induced by an increasing strain. A qualitative comparison with TiN (Fig. 10), reveals that elongations of $\approx 20 \%$ (Fig. 11) and $\approx 24 \%$ (Fig. 12) are necessary to completely open the crack in $\mathrm{Ti}_{0.5} \mathrm{Al}_{0.5} \mathrm{~N}$ and $\mathrm{Ti}_{0.25} \mathrm{Al}_{0.75} \mathrm{~N}$, respectively. Overall, TiN(111) presents greater toughness than $\mathrm{Ti}_{0.5} \mathrm{Al}_{0.5} \mathrm{~N}(111)$ [Table II and Fig. 2(c)]. This is due to the fact that, while both materials fracture at $20 \%$ strain, the binary compound reaches mechanical yielding at a much higher elongation than the ternary alloy. In contrast, $\mathrm{Ti}_{0.25} \mathrm{Al}_{0.75} \mathrm{~N}(111)$ solid solutions exhibit equal strength, but higher toughness, than TiN(111) owing to slow bond fraying, which delays fracture up to an elongation of 22-24\% (Fig. 12).

The transformation toughening effect observed via [110] and [111] elongation of $\mathrm{B} 1 \mathrm{Ti}_{0.5} \mathrm{Al}_{0.5} \mathrm{~N}$ and $\mathrm{Ti}_{0.25} \mathrm{Al}_{0.75} \mathrm{~N}$ is less pronounced than the mechanism induced by [001] strain because these deformation paths offer lower flexibility toward B1 $\rightarrow$ tetragonal $\rightarrow$ B4 transitions (Fig. 6). Indeed, the bonding geometries visible in plastically deformed domains of $\mathrm{Ti}_{0.5} \mathrm{Al}_{0.5} \mathrm{~N}(110)$ (Fig. 8), $\mathrm{Ti}_{0.25} \mathrm{Al}_{0.75} \mathrm{~N}$ (110) (Fig. 9), $\mathrm{Ti}_{0.5} \mathrm{Al}_{0.5} \mathrm{~N}(111)$ (Fig. 11), and $\mathrm{Ti}_{0.25} \mathrm{Al}_{0.75} \mathrm{~N}(111)$ (Fig. 12) suggest that local structural amorphization takes place in response to extreme external stresses. Notably, this characteristic is not observable in TiN and $\mathrm{Ti}_{0.75} \mathrm{Al}_{0.25} \mathrm{~N}$, likely due to high stability of octahedral bonding configurations [see Figs. 7(c) and 7(d) in Ref. [32]) along [001], [110], and [111] uniaxial transformation paths.

Nanoindentation mechanical testing of single-crystal B1 TiN films demonstrates its inherently brittle nature [30]. On the other hand, experimental information for the mechanical properties of monolithic $\mathrm{B} 1 \mathrm{Ti}_{1-x} \mathrm{Al}_{x} \mathrm{~N}$ solid solutions with $x \geqslant 0.5$ are not currently available. Nevertheless, the AIMD predictions of this work are qualitatively supported by the experimental observations of Bartosik et al. [27], which indicated that the resistance to fracture of singlephase $\mathrm{B} 1$ nanocrystalline $\mathrm{Ti}_{0.4} \mathrm{Al}_{0.6} \mathrm{~N}$ solid solutions benefits from the formation of hexagonal B4 domains upon loading. Other experimental investigations also suggest that dual-phase wurtzite/cubic $\mathrm{Ti}_{1-x} \mathrm{Al}_{x} \mathrm{~N}(x \approx 0.75)$ films possess high hardness (30 GPa) [60], which indirectly contributes to enhance the materials' toughness. Moreover, in B1-ZrN/B1ZrAlN [61] and B1-CrN/B1-AlN [62] superlattices, stressinduced $\mathrm{B} 1 \rightarrow \mathrm{B} 4$ transformation in $\mathrm{B} 1$ AlN-rich domains has been demonstrated to significantly increase the materials' toughness.

The results of this work provide fundamental insights of the mechanical properties of $\mathrm{B} 1(\mathrm{Ti}, \mathrm{Al}) \mathrm{N}$ solid solution ceramics during use. However, it is important to underline that the macroscopic mechanical behavior and resistance to fracture of polycrystalline $\mathrm{B} 1(\mathrm{Ti}, \mathrm{Al}) \mathrm{N}$ coatings are primarily controlled by microstructural features such as grain size, texture, and grain boundary properties. For example, cracks can more easily initiate and propagate at the interfaces between crystallites where the density is lower and voids may be present. Nonetheless, the toughening mechanisms observed in AIMD simulations can operate within (Ti,Al)N grains of sufficiently large size (less affected by grain boundary properties), when tensile stresses build up inside the grain. The elongations at fracture $\delta_{f}$ shown in Fig. 2 and Table II are indicative of the relatively ability of $\mathrm{B} 1(\mathrm{Ti}, \mathrm{Al}) \mathrm{N}$ alloys with different metal compositions to endure deformation by undergoing local ( $\mathrm{nm}$ length-scale) modifications in the bonding network.

It should also be emphasized that our present AIMD simulations pertain the mechanical behavior of $(\mathrm{Ti}, \mathrm{Al}) \mathrm{N}$ solid solutions at $300 \mathrm{~K}$. At this temperature, spinodal 
decomposition is kinetically blocked, i.e., the temperature is not high enough to activate diffusion of vacancies (vacancy migration in $\mathrm{B} 1(\mathrm{Ti}, \mathrm{Al}) \mathrm{N}$ systems requires energies in the range $\approx 2.5-4.5 \mathrm{eV}$ [63-66]). In general, if the operation temperature of $(\mathrm{Ti}, \mathrm{Al}) \mathrm{N}$ coatings remains below $\approx 1000 \mathrm{~K}-$ typically the onset for decomposition - we find it unlikely that the spinodal decomposition process may occur faster than the strain-mediated lattice transformations seen here.

At a fundamental electronic-structure level, a relatively high Al metal content $(\approx 60 \%)$ is expected to maximize the hardness of $\mathrm{B} 1$ (Ti,Al)N alloys. The effect stems from the fact that $\approx 8.4 \mathrm{e}^{-} /$f.u. in B1-structure transition-metal (carbo)nitride solid solutions fully populate strong $p-d$ metal/ $\mathrm{N}$ bonding states while leaving shear-sensitive $d-d$ metallic states empty [49]. In contrast, a low occupancy of $d$ states is detrimental for the ability of (Ti,Al)N to form metallic bonds upon shearing. That, in turn, has been suggested as a possible cause of brittleness [51]. Consistent with the analysis of Ref. [51], phenomenological ductility/brittleness predictions based on elastic constant values would also (erroneously) indicate that $\mathrm{Al}$ substitutions degrade the (Ti, $\mathrm{Al}) \mathrm{N}$ resistance to fracture. For example, according to the criterion proposed by Pettifor [67], the decrease in $C_{12}-C_{44}$ Cauchy's pressure suggests that $\mathrm{B} 1 \mathrm{Ti}_{1-x} \mathrm{Al}_{x} \mathrm{~N}$ solid solutions become progressively more brittle for increasing $x$ (see Fig. 1 in Ref. [46]). However, density functional theory (DFT) predictions of toughness vs brittleness in ( $\mathrm{Ti}, \mathrm{Al}) \mathrm{N}$ [51], primarily based on the analyses of the alloy elastic deformation, are unsuited to reveal the occurrence of transformation toughening mechanisms in the plastic regime.

$\mathrm{B} 1(\mathrm{Ti}, \mathrm{Al}) \mathrm{N}$ ceramics are of enormous technological importance due to age-hardening induced by spinodal decomposition at elevated temperatures [68]. However, while the spinodal mechanism is kinetically blocked at ambient conditions, DFT calculations at $0 \mathrm{~K}$ show that an $\mathrm{Al}$ metal content larger than $\approx 0.7$ renders $\mathrm{Ti}_{1-x} \mathrm{Al}_{x} \mathrm{~N}$ solid solutions energetically more stable in the wurtzite than in the rocksalt structure (see Fig. 3(a) in Ref. [69]). The results of present AIMD simulations, combined with those of Ref. [69], evidence a correlation between the phase stability of the alloys and their inherent room-temperature toughness vs brittleness.

The mechanical behavior predicted by AIMD for TiN and $\mathrm{Ti}_{0.75} \mathrm{Al}_{0.25} \mathrm{~N}$ (Figs. 3, 7, 10, and Ref. [32]) indicates that an $\mathrm{Al}$ content much lower than 0.5 causes $\mathrm{B} 1 \mathrm{Ti}_{1-x} \mathrm{Al}_{x} \mathrm{~N}$ embrittlement. Presumably, the energy required to induce cleavage in these two systems is smaller than the one necessary to activate any local lattice transformation during uniaxial strain. In contrast, our results suggest that tuning the $\mathrm{Ti}_{1-x} \mathrm{Al}_{x} \mathrm{~N}$ metal composition around the threshold value $x \approx 0.7$ [69] can be used to optimize the combination of strength and toughness of B1-structure alloys. Indeed, the relatively small $E_{\mathrm{B} 1}-E_{\mathrm{B} 4}$ energy difference calculated for $\mathrm{Ti}_{0.5} \mathrm{Al}_{0.5} \mathrm{~N}$ [69] enables $\mathrm{B} 1 \rightarrow \mathrm{B} 4$-like transformations during [001] tensile deformation (Figs. 3 and 5), thus dissipating accumulated stresses and enhancing the material resistance to fracture. On the other hand, $\mathrm{Ti}_{0.25} \mathrm{Al}_{0.75} \mathrm{~N}$ solid solutions (which can be synthesized as B1 single-phase films [6,7]) would favorably crystallize in the $\mathrm{B} 4$ polymorph structure at ambient conditions [69]. Accordingly, $\mathrm{Ti}_{0.25} \mathrm{Al}_{0.75} \mathrm{~N}$ is thermodynamically more inclined than $\mathrm{Ti}_{0.5} \mathrm{Al}_{0.5} \mathrm{~N}$ to activate $\mathrm{B} 1 \rightarrow \mathrm{B} 4$ transfor- mations under load. Consistent with this observation, AIMD shows that, for elongations progressively increasing beyond the yield point of the material, wurtzite-like domains grow faster in $\mathrm{Ti}_{0.25} \mathrm{Al}_{0.75} \mathrm{~N}(001)$ than in $\mathrm{Ti}_{0.5} \mathrm{Al}_{0.5} \mathrm{~N}(001)$. This is reflected by a greater drop in the stress of $\mathrm{Ti}_{0.25} \mathrm{Al}_{0.75} \mathrm{~N}(001)$ visible between $12 \%$ and $14 \%$ strain [Fig. 2(a)].

That metastability is beneficial to enhance the mechanical performance of ceramics is not a new concept. For example, it has been shown that tuning the electron concentration to values near $9.5 \mathrm{e}^{-} /$f.u. sets hexagonal and cubic polymorph structures of transition-metal carbonitrides to similar energies. This, in turn, promotes formation of hexagonal stacking faults in cubic alloys, thus increasing hardness by hindering dislocation motion across the faults [70,71]. Similarly, plastic deformation along 111 faults in B1 refractory carbonitrides can be assisted by providing facile deformation paths: the energy barrier of $\{111\}\langle 1-10\rangle$ slip is reduced by synchro-shear mechanisms in $\mathrm{B} 1 \mathrm{Ti}_{0.5} \mathrm{~W}_{0.5} \mathrm{~N}$ solid solutions and $\mathrm{B} 1-\mathrm{TiN} / \mathrm{B} 1-\mathrm{WN}_{x}$ superlattices due to the preference of $\mathrm{B} 1 \mathrm{WN}$-rich domains to transform in more stable hexagonal WC-structures [72,73]. Analogous to the experimental findings for multilayer films of Yalamanchili et al. [61] and Schlögl et al. [62], in this work we show that alloying (in ideal defect-free structures) transition-metal nitrides with AlN can-beside spinodal agehardening at elevated temperatures-enable $\mathrm{B} 1 \rightarrow \mathrm{B} 4$ transformation toughening mechanisms at $300 \mathrm{~K}$, i.e., much lower than the typical brittle-to-ductile transition temperatures of refractory ceramics $[29,31]$.

\section{CONCLUSIONS}

AIMD simulations at $300 \mathrm{~K}$ are used to determine the inherent tensile strength, toughness, and resistance to fracture of defect-free $\mathrm{B} 1 \mathrm{Ti}_{1-x} \mathrm{Al}_{x} \mathrm{~N}$ solid solutions $(0 \leqslant x \leqslant 0.75)$. The results show that TiN and $\mathrm{Ti}_{0.75} \mathrm{Al}_{0.25} \mathrm{~N}$ are strong materials, but cleave at their yield point via sudden bond snapping. In contrast, $\mathrm{Ti}_{0.5} \mathrm{Al}_{0.5} \mathrm{~N}$ and $\mathrm{Ti}_{0.25} \mathrm{Al}_{0.75} \mathrm{~N}$ exhibit similar strength, but significantly higher toughness than $\mathrm{TiN}$ and $\mathrm{Ti}_{0.75} \mathrm{Al}_{0.25} \mathrm{~N}$, due to the activation of local lattice transformations in the plastic-response regime that dissipates stress, thus preventing brittle failure. Overall, $\mathrm{B} 1 \mathrm{Ti}_{0.25} \mathrm{Al}_{0.75} \mathrm{~N}$ solid solutions exhibit the best combination of room-temperature strength and toughness, due to an energetic preference toward the more stable B4 polymorph structure.

Combined with previous $a b$ initio results and supported by experimental findings, our theoretical investigations show that tuning the energy difference of competing B1 vs B4 structures is a viable approach to control the inherent toughness of B1 transition-metal-Al-N solid solutions. More generally, present AIMD simulations emphasize the importance of exploiting phase metastability as a trigger for activating transformation toughening and plastic deformation in materials at extreme mechanical-loading conditions.

\section{ACKNOWLEDGMENTS}

All simulations were carried out using the resources provided by the Swedish National Infrastructure for Computing (SNIC), on the Clusters located at the National Supercomputer Centre (NSC) in Linköping, the Center for High 
Performance Computing (PDC) in Stockholm, and at the High Performance Computing Center North (HPC2N) in Umeå, Sweden. We gratefully acknowledge financial support from the Competence Center Functional Nanoscale Materials (FunMat-II) (Vinnova Grant No. 2016-05156), the Swedish Research Council (VR) through Grant No. 2019-05600, the
Swedish Government Strategic Research Area in Materials Science on Functional Materials at Linköping University (Faculty Grant SFO-Mat-LiU No. 2009-00971), and the Knut and Alice Wallenberg Foundation through Wallenberg Scholar project (Grant No. 2018.0194). D.G.S. gratefully acknowledges financial support from the Olle Engkvist Foundation.
[1] O. Knotek, M. Böhmer, and T. Leyendecker, On structure and properties of sputtered $\mathrm{Ti}$ and $\mathrm{Al}$ based hard compound films, J. Vac. Sci. Technol. A 4, 2695 (1986).

[2] G. Greczynski, L. Hultman, and M. Odén, X-ray photoelectron spectroscopy studies of $\mathrm{Ti}_{1-x} \mathrm{Al}_{x} \mathrm{~N}(0 \leqslant x \leqslant 0.83)$ hightemperature oxidation: The crucial role of $\mathrm{Al}$ concentration, Surf. Coat. Technol. 374, 923 (2019).

[3] B. Alling, M. Oden, L. Hultman, and I. A. Abrikosov, Pressure enhancement of the isostructural cubic decomposition in $\mathrm{Ti}_{1-x} \mathrm{Al}_{x} \mathrm{~N}$, Appl. Phys. Lett. 95, 181906 (2009).

[4] N. Shulumba, O. Hellman, Z. Raza, B. Alling, J. Barrirero, F. Mücklich, I. A. Abrikosov, and M. Oden, Lattice Vibrations Change the Solid Solubility of an Alloy at High Temperatures, Phys. Rev. Lett. 117, 205502 (2016).

[5] I. Petrov, P. B. Barna, L. Hultman, and J. E. Greene, Microstructural evolution during film growth, J. Vac. Sci. Technol. A 21, S117 (2003).

[6] L. J. S. Johnson, M. Thuvander, K. Stiller, M. Oden, and L. Hultman, Spinodal decomposition of $\mathrm{Ti}_{0.33} \mathrm{Al}_{0.67} \mathrm{~N}$ thin films studied by atom probe tomography, Thin Solid Films 520, 4362 (2012).

[7] I. Endler, M. Höhn, M. Herrmann, R. Pitonak, S. Ruppi, M. Schneider, H. van den Berg, and H. Westphal, Novel aluminumrich $\mathrm{Ti}_{1-x} \mathrm{Al}_{x} \mathrm{~N}$ coatings by LPCVD, Surf. Coat. Technol. 203, 530 (2008).

[8] P. H. Mayrhofer, A. Hörling, L. Karlsson, J. Sjölen, T. Larsson, C. Mitterer, and L. Hultman, Self-organized nanostructures in the Ti-Al-N system, Appl. Phys. Lett. 83, 2049 (2003).

[9] J. A. Garber and A. V. Granato, Theory of the temperature dependence of second-order elastic constants in cubic materials, Phys. Rev. B 11, 3990 (1975).

[10] Y. P. Varshni, Temperature dependence of the elastic constants, Phys. Rev. B 2, 3952 (1970).

[11] I. A. Abrikosov, A. Knutsson, B. Alling, F. Tasnadi, H. Lind, L. Hultman, and M. Oden, Phase stability and elasticity of TiAlN, Materials 4, 1599 (2011).

[12] A. Hörling, L. Hultman, M. Oden, J. Sjölen, and L. Karlsson, Thermal stability of arc evaporated high aluminum-content $\mathrm{Ti}_{1-x} \mathrm{Al}_{x} \mathrm{~N}$ thin films, J. Vac. Sci. Technol. A 20, 1815 (2002).

[13] K. Kutschej, P. H. Mayrhofer, M. Kathrein, P. Polcik, R. Tessadri, and C. Mitterer, Structure, mechanical and tribological properties of sputtered $\mathrm{Ti}_{1-x} \mathrm{Al}_{x} \mathrm{~N}$ coatings with $0.5 \leqslant x \leqslant$ 0.75, Surf. Coat. Technol. 200, 2358 (2005).

[14] D. Music, R. W. Geyer, and J. M. Schneider, Recent progress and new directions in density functional theory based design of hard coatings, Surf. Coat. Technol. 286, 178 (2016).

[15] B. Alling, P. Steneteg, C. Tholander, F. Tasnadi, I. Petrov, J. E. Greene, and L. Hultman, Configurational disorder effects on adatom mobilities on $\mathrm{Ti}_{1-x} \mathrm{Al}{ }_{x} \mathrm{~N}(001)$ surfaces from first principles, Phys. Rev. B 85, 245422 (2012).
[16] D. Music and J. M. Schneider, $A b$ initio study of $\mathrm{Ti}_{0.5} \mathrm{Al}_{0.5} \mathrm{~N}(001)$-residual and environmental gas interactions, New J. Phys. 15, 073004 (2013).

[17] C. Kunze, D. Music, M. T. Baben, J. M. Schneider, and G. Grundmeier, Temporal evolution of oxygen chemisorption on TiAlN, Appl Surf. Sci. 290, 504 (2014).

[18] P. H. Mayrhofer, F. D. Fischer, H. J. Bohm, C. Mitterer, and J. M. Schneider, Energetic balance and kinetics for the decomposition of supersaturated $\mathrm{Ti}_{1-x} \mathrm{Al}_{x} \mathrm{~N}$, Acta Mater. 55, 1441 (2007).

[19] H. Lind, F. Tasnadi, and I. A. Abrikosov, Systematic theoretical search for alloys with increased thermal stability for advanced hard coatings applications, New J. Phys. 15, 095010 (2013).

[20] N. Norrby, H. Lind, G. Parakhonskiy, M. P. Johansson, F. Tasnadi, L. S. Dubrovinsky, N. Dubrovinskaia, I. A. Abrikosov, and $\mathrm{M}$. Oden, High pressure and high temperature stabilization of cubic AlN in $\mathrm{Ti}_{0.60} \mathrm{Al}_{0.40} \mathrm{~N}$, J. Appl. Phys. 113, 053515 (2013).

[21] R. Rachbauer, D. Holec, and P. H. Mayrhofer, Phase stability and decomposition products of Ti-Al-Ta-N thin films, Appl. Phys. Lett. 97, 151901 (2010).

[22] Y. H. Chen, J. J. Roa, C. H. Yu, M. P. Johansson-Joesaar, J. M. Andersson, M. J. Anglada, M. Oden, and L. Rogström, Enhanced thermal stability and fracture toughness of TiAlN coatings by $\mathrm{Cr}$, $\mathrm{Nb}$ and $\mathrm{V}$-alloying, Surf. Coat. Technol. 342, 85 (2018).

[23] M. Mikula, M. Truchlý, D. G. Sangiovanni, D. Plašienka, T. Roch, M. Gregor, P. Ďurina, M. Janík, and P. Kúš, Experimental and computational studies on toughness enhancement in Ti-AlTa-N quaternaries, J. Vac. Sci. Technol. A 35, 060602 (2017).

[24] W. M. Seidl, M. Bartosik, S. Kolozsvári, H. Bolvardi, and P. $\mathrm{H}$. Mayrhofer, Influence of Ta on the fracture toughness of arc evaporated Ti-Al-N, Vacuum 150, 24 (2018).

[25] M. Mikula, D. Plasienka, D. G. Sangiovanni, M. Sahul, T. Roch, M. Truchly, M. Gregor, L. u. Caplovic, A. Plecenik, and P. Kus, Toughness enhancement in highly $\mathrm{NbN}$-alloyed Ti-Al-N hard coatings, Acta Mater. 121, 59 (2016).

[26] A. E. Santana, A. Karimi, V. H. Derflinger, and A. Schutze, Relating hardness-curve shapes with deformation mechanisms in TiAlN thin films enduring indentation, Mater. Sci. Eng. A 406, 11 (2005).

[27] M. Bartosik, C. Rumeau, R. Hahn, Z. L. Zhang, and P. H. Mayrhofer, Fracture toughness and structural evolution in the TiAlN system upon annealing, Sci. Rep. 7, 16476 (2017).

[28] A. Shekhawat and R. O. Ritchie, Toughness and strength of nanocrystalline graphene, Nat. Commun. 7, 10546 (2016).

[29] D. J. Rowcliffe and G. E. Hollox, Hardness anisotropy, deformation mechanisms and brittle-to-ductile transition in carbide, J. Mater. Sci. 6, 1270 (1971). 
[30] H. Kindlund, D. G. Sangiovanni, L. Martinez-de-Olcoz, J. Lu, J. Jensen, J. Birch, I. Petrov, J. E. Greene, V. Chirita, and L. Hultman, Toughness enhancement in hard ceramic thin films by alloy design, APL Mater. 1, 042104 (2013).

[31] J. F. Li and R. Watanabe, Brittle-to-ductile transition and hightemperature deformation in $\mathrm{ZrO}_{2}\left(\mathrm{Y}_{2} \mathrm{O}_{3}\right)$ and $\mathrm{Al}_{2} \mathrm{O}_{3}$ ceramics as evaluated by small punch test, Mater. Trans. 40, 508 (1999).

[32] D. G. Sangiovanni, Inherent toughness and fracture mechanisms of refractory transition-metal nitrides via densityfunctional molecular dynamics, Acta Mater. 151, 11 (2018).

[33] R. Car and M. Parrinello, Unified Approach for Molecular Dynamics and Density-Functional Theory, Phys. Rev. Lett. 55, 2471 (1985).

[34] G. Kresse and J. Furthmuller, Efficiency of ab initio total energy calculations for metals and semiconductors using a plane-wave basis set, Comput. Mater. Sci. 6, 15 (1996).

[35] G. Kresse and J. Furthmuller, Efficient iterative schemes for $a b$ initio total-energy calculations using a plane-wave basis set, Phys. Rev. B 54, 11169 (1996).

[36] G. Kresse and D. Joubert, From ultrasoft pseudopotentials to the projector augmented-wave method, Phys. Rev. B 59, 1758 (1999).

[37] P. E. Blöchl, Projector augmented wave method, Phys. Rev. B 50, 17953 (1994).

[38] J. P. Perdew, K. Burke, and M. Ernzerhof, Generalized Gradient Approximation Made Simple, Phys. Rev. Lett. 77, 3865 (1996).

[39] M. Parrinello and A. Rahman, Polymorphic transitions in single-crystals -A new molecular dynamics method, J. Appl. Phys. 52, 7182 (1981).

[40] D. G. Sangiovanni, F. Tasnadi, M. Oden, and I. A. Abrikosov (unpublished).

[41] W. Humphrey, A. Dalke, and K. Schulten, VMD: Visual molecular dynamics, J. Mol. Graphics Modell. 14, 33 (1996).

[42] Note that lateral $\sigma$ and $\sigma$ stresses are not shown.

[43] P. Steneteg, O. Hellman, O. Y. Vekilova, N. Shulumba, F. Tasnadi, and I. A. Abrikosov, Temperature dependence of TiN elastic constants from $a b$ initio molecular dynamics simulations, Phys. Rev. B 87, 094114 (2013).

[44] D. Holec, M. Friak, J. Neugebauer, and P. H. Mayrhofer, Trends in the elastic response of binary early transition metal nitrides, Phys. Rev. B 85, 064101 (2012).

[45] D. Edström, D. G. Sangiovanni, L. Hultman, and V. Chirita, Effects of atomic ordering on the elastic properties of TiN- and VN-based ternary alloys, Thin Solid Films 571, 145 (2014).

[46] F. Tasnadi, I. A. Abrikosov, L. Rogström, J. Almer, M. P. Johansson, and M. Oden, Significant elastic anisotropy in $\mathrm{Ti}_{1-x} \mathrm{Al}_{x} \mathrm{~N}$ alloys, Appl. Phys. Lett. 97, 231902 (2010).

[47] D. G. Sangiovanni, V. Chirita, and L. Hultman, Electronic mechanism for toughness enhancement in $\mathrm{Ti}_{x} M_{1-x} \mathrm{~N}(M=$ Mo and W), Phys. Rev. B 81, 104107 (2010).

[48] N. Shulumba, O. Hellman, L. Rogström, Z. Raza, F. Tasnadi, I. A. Abrikosov, and M. Oden, Temperature-dependent elastic properties of $\mathrm{Ti}_{1-x} \mathrm{Al}_{x} \mathrm{~N}$ alloys, Appl. Phys. Lett. 107, 231901 (2015).

[49] S. H. Jhi, J. Ihm, S. G. Louie, and M. L. Cohen, Electronic mechanism of hardness enhancement in transition-metal carbonitrides, Nature (London) 399, 132 (1999).

[50] D. G. Sangiovanni, L. Hultman, and V. Chirita, Supertoughening in B1 transition metal nitride alloys by increased valence electron concentration, Acta Mater. 59, 2121 (2011).
[51] D. G. Sangiovanni, V. Chirita, and L. Hultman, Toughness enhancement in TiAlN-based quarternary alloys, Thin Solid Films 520, 4080 (2012).

[52] It is important to note that calculated stresses differ quantitatively with those reported in Ref. [32] due to previous AIMD investigations employing smaller supercells, different deformation steps, and a different approximation for description of electronic exchange/correlation. In addition, in previous simulations [32], the equilibrated supercell structural parameters have been manually optimized until $\left|\sigma_{\mathrm{ii}}\right|$ stress values were smaller than $\approx 1-2 \mathrm{GPa}$, which is less accurate than the criterion $\left(\left|\sigma_{\mathrm{ii}}\right| \leqslant\right.$ $0.3 \mathrm{GPa}$ ) used in this work.

[53] R. F. Zhang and S. Veprek, Deformation paths and atomistic mechanism of B4 $\rightarrow$ B1 phase transformation in aluminium nitride, Acta Mater. 57, 2259 (2009).

[54] G.-R. Qian, X. Dong, X.-F. Zhou, Y. Tian, A. R. Oganov, and H.-T. Wang, Variable cell nudged elastic band method for studying solid-solid structural phase transitions, Comput. Phys. Commun. 184, 2111 (2013).

[55] J. Cai and N. X. Chen, Microscopic mechanism of the wurtziteto-rocksalt phase transition of the group-III nitrides from first principles, Phys. Rev. B 75, 134109 (2007).

[56] A. M. Saitta and F. Decremps, Unifying description of the wurtzite-to-rocksalt phase transition in wide-gap semiconductors: The effect of d electrons on the elastic constants, Phys. Rev. B 70, 035214 (2004).

[57] S. E. Boulfelfel, D. Zahn, Y. Grin, and S. Leoni, Walking the Path from B4- to B1-type Structures in GaN, Phys. Rev. Lett. 99, 125505 (2007).

[58] B. Alling, A. V. Ruban, A. Karimi, O. E. Peil, S. I. Simak, L. Hultman, and I. A. Abrikosov, Mixing and decomposition thermodynamics of $\mathrm{c}-\mathrm{Ti}_{1-x} \mathrm{Al}_{x} \mathrm{~N}$ from first-principles calculations, Phys. Rev. B 75, 045123 (2007).

[59] W. Liu, X. Liu, W. T. Zheng, and Q. Jiang, Surface energies of several ceramics with $\mathrm{NaCl}$ structure, Surf. Sci. 600, 257 (2006).

[60] T. Shimizu, Y. Teranishi, K. Morikawa, H. Komiya, T. Watanabe, H. Nagasaka, and M. Yang, Impact of pulse duration in high power impulse magnetron sputtering on the lowtemperature growth of wurtzite phase $(\mathrm{Ti}, \mathrm{Al}) \mathrm{N}$ films with high hardness, Thin Solid Films 581, 39 (2015).

[61] K. Yalamanchili, I. C. Schramm, E. Jimenez-Pique, L. Rogström, F. Mücklich, M. Oden, and N. Ghafoor, Tuning hardness and fracture resistance of $\mathrm{ZrN} / \mathrm{Zr}_{0.63} \mathrm{Al}_{0.37} \mathrm{~N}$ nanoscale multilayers by stress-induced transformation toughening, Acta Mater. 89, 22 (2015)

[62] M. Schlögl, C. Kirchlechner, J. Paulitsch, J. Keckes, and P. H. Mayrhofer, Effects of structure and interfaces on fracture toughness of CrN/AlN multilayer coatings, Scr. Mater. 68, 917 (2013).

[63] G. A. Almyras, D. G. Sangiovanni, and K. Sarakinos, Semiempirical force-field model for the $\mathrm{Ti}_{1-x} \mathrm{Al}_{x} \mathrm{~N}(0 \leqslant x \leqslant 1)$ system, Materials 12, 215 (2019).

[64] D. Gambino, D. G. Sangiovanni, B. Alling, and I. A. Abrikosov, Nonequilibrium $a b$ initio molecular dynamics determination of Ti monovacancy migration rates in B1 TiN, Phys. Rev. B 96, 104306 (2017).

[65] D. G. Sangiovanni, B. Alling, P. Steneteg, L. Hultman, and I. A. Abrikosov, Nitrogen vacancy, self-interstitial diffusion, and Frenkel-pair formation/dissociation in B1 TiN studied by 
$a b$ initio and classical molecular dynamics with optimized potentials, Phys. Rev. B 91, 054301 (2015).

[66] D. G. Sangiovanni, Mass transport properties of quasiharmonic vs anharmonic transition-metal nitrides, Thin Solid Films 688, 137297 (2019).

[67] D. G. Pettifor, Theoretical predictions of structure and related properties of intermetallics, Mater. Sci. Technol. 8, 345 (1992).

[68] A. Knutsson, J. Ullbrand, L. Rogström, N. Norrby, L. J. S. Johnson, L. Hultman, J. Almer, M. P. Johansson Jöesaar, B. Jansson, and M. Odén, Microstructure evolution during the isostructural decomposition of TiAlN - A combined in situ small angle $\mathrm{x}$-ray scattering and phase field study, J. Appl. Phys. 113, 213518 (2013).

[69] D. Holec, R. Rachbauer, L. Chen, L. Wang, D. Luef, and P. H. Mayrhofer, Phase stability and alloy-related trends in Ti-Al-N,
Zr-Al-N and Hf-Al-N systems from first principles, Surf. Coat. Technol. 206, 1698 (2011).

[70] H. W. Hugosson, U. Jansson, B. Johansson, and O. Eriksson, Restricting dislocation movement in transition metal carbides by phase stability tuning, Science 293, 2434 (2001).

[71] T. Joelsson, L. Hultman, H. W. Hugosson, and J. M. MolinaAldareguia, Phase stability tuning in the $\mathrm{Nb}_{x} \mathrm{Zr}_{1-x} \mathrm{~N}$ thin-film system for large stacking fault density and enhanced mechanical strength, Appl. Phys. Lett. 86, 131922 (2005).

[72] D. G. Sangiovanni, L. Hultman, V. Chirita, I. Petrov, and J. E. Greene, Effects of phase stability, lattice ordering, and electron density on plastic deformation in cubic TiWN pseudobinary transition-metal nitride alloys, Acta Mater. 103, 823 (2016).

[73] J. Buchinger, N. Koutna, Z. Chen, Z. L. Zhang, P. H. Mayrhofer, D. Holec, and M. Bartosik, Toughness enhancement in TiN/WN superlattice thin films, Acta Mater. 172, 18 (2019). 